Solano, J. P., Aguilar, A. T., Madrigal, M. P., Pérez, W., Vargas, C. A., Chavarría, M. M., \& Denyer, P. (2021). Naturaleza y estructura geológica del borde costero del noroeste de Costa Rica. Revista de Biología Tropical, 69(Suppl. 2), S36-S59. https://doi.org/10.15517/rbt.v69iS2.48306

\title{
Naturaleza y estructura geológica del borde costero del noroeste de Costa Rica
}

Juan Pablo Solano ${ }^{1,2}$; (D) https://orcid.org/0000-0001-5498-9924

Ana Teresita Aguilar ${ }^{1}$; (D) https://orcid.org/0000-0003-3567-2504

María del Pilar Madrigal ${ }^{1,3}$; (D) https://orcid.org/0000-0002-2089-0560

Wendy Pérez ${ }^{4}$; D https://orcid.org/0000-0002-1982-0979

Carlos Alonso Vargas5; (iD https://orcid.org/0000-0002-6079-3765

María Marta Chavarría6; (D https://orcid.org/0000-0001-6378-1893

Percy Denyer ${ }^{1,3}$; (D) https://orcid.org/0000-0002-8006-9889

1. Centro de Investigación en Ciencias Geológicas, Universidad de Costa Rica, San José, Costa Rica;

jpsm6400@gmail.com, percy.denyer@ucr.ac.cr, anatere.aguilar@gmail.com, mariadelpilar.madrigal@ucr.ac.cr

2. Universidad Autónoma de San Luis Potosí, San Luis Potosí, México; A332913@alumnos.uaslp.mx

3. Escuela Centroamericana de Geología, Universidad de Costa Rica, San José, Costa Rica; percy.denyer@ucr.ac.cr, mariadelpilar.madrigal@ucr.ac.cr

4. Erwatec Ingenieurgesellschaft GmbH, Kiel, Alemania; wenppf@yahoo.com

5. Barrick Gold Corporation, Toronto, Ontario, Canadá; alonsovcr@gmail.com

6. Área de Conservación Guanacaste, Guanacaste, Costa Rica; mmchava@acguanacaste.ac.cr

$$
\text { Recibido 01-XII-2020. C Corregido 28-I-2021. Aceptado 24-II-2021. }
$$

\section{ABSTRACT \\ Geological background and structure of the northwestern coastline of Costa Rica}

Introduction: The Costa Rican northwestern coastline has a wide geological uniqueness that exhibits rocks from different environments such as abyssal plane, continental slope, continental platform, volcanic eruptions (effusive, explosive, and submarine), coastal, erosional (fluvial and gravitatory), intrusions, and upper mantle rocks.

Objective: To present the geologic state of the art of the northwestern coastline of Costa Rica through the bibliographic review of geochemical, petrologic, structural, paleontological and geochronological data.

Methods: A bibliographic revision was done to propose a state of the art of northwestern coastline of Costa Rica. Results: The geologic record shows eleven stages from the Jurassic to the Holocene. These stages were regrouped from petrologic, structural, geochronologic, stratigraphic and paleontological interpretations in three depositional stages and four compressive tectonic phases.

Conclusions: The first depositional stage is volcanic with oceanic affinity between the Jurassic and Upper Cretaceous. The second has a sedimentary predominance with an age range between the Upper Cretaceous and the Miocene. The last depositional stage is a volcanic (effusive and explosive) from the Pliocene until the present. The tectonic phases are associate with different interactions between tectonic plates. The first phase triggered the Santa Elena Ophiolite obduction during the Early Cretaceous. The second phase occurred in the Early Upper Cretaceous - Campanian and is recognized by its current position and surrounding structures. The third phase lasted from the Upper Eocene until the Miocene and its main result was the folding of the Bahía de Salinas sedimentary rocks. Finally, the Quaternary phase created a tilt axis and the aperture for the deposition of pyroclastic density currents in front of the Guanacaste volcanic ridge.

Key words: Santa Elena ophiolite; geologic history; stress; volcanic eruption; Guanacaste; tectonic phase; sedimentary rock. 
El contexto geológico del sector noroeste de Costa Rica comprende rocas de edades entre el Jurásico y el Holoceno ( 201.3 Ma actualidad). El basamento está constituido por rocas de afinidad oceánica con una edad entre el Hauteriviano y el Cenomaniano ( 132.9 $\sim 93.9$ Ma; Madrigal, Gazel \& Denyer, 2019). La continuación del registro geológico está dada por rocas sedimentarias de diversos orígenes que abarcan del Cretácico Superior al Oligoceno (100.5 - 23.03 Ma; Aguilar \& Denyer, 2019). Con el final del registro sedimentario, hubo un cambio de régimen en los depósitos, con predominancia a rocas extrusivas de tipo piroclástico y en menor cantidad coladas de lava durante el Plio - Pleistoceno (5.33 - 0.012 Ma) (Alvarado \& Denyer, 2019; Barrantes, 2018; Solano, Denyer, \& Pérez, 2019; Solano, Denyer, Pérez, Lücke, \& Madrigal, 2019).

Seguido a esto, se presentaron eventos preferencialmente efusivos y en menor medida extrusivos de la Cordillera de Guanacaste (Alvarado \& Denyer, 2019). El final del registro litológico lo comprenden los procesos de denudación activa y reciente (Aguilar \& Denyer, 2019; Alvarado \& Denyer, 2019). Estas rocas han sido afectadas por diversas etapas de compresión y tensión producto de esfuerzos regionales, lo cual ha provocado su configuración actual.

Se seleccionó como área de estudio las hojas cartográficas, a escala 1:50 000, Bahía Salinas, Murciélago, Peñas Blancas y Santa Elena del Instituto Geográfico Nacional, debido a que, en estas cuatro hojas se presenta el registro litológico con edades desde el Jurásico (rocas más antiguas de Costa Rica: 190.8 Ma) al Holoceno (época en la que nos encontramos en la actualidad) aflorante en la costa del noroeste de Costa Rica (Fig. 1).

Por tanto, esta investigación presenta la caracterización de las rocas y eventos geológicos del área de estudio sobre los cuales se desarrolla la biósfera actual, mediante datos de tipo cartográfico, geoquímico, petrológico, estructural, paleontológico y radiométrico, con el fin de reconstruir los eventos, productos y etapas de deformación desde el Jurásico a la actualidad.

\section{MATERIALES Y MÉTODOS}

Se desarrolló una síntesis geológica del área de estudio para un público biológico y de ciencias afines, a diferencia de la propuesta de Denyer (2019), que es para un público geológico. Este estado del arte tiene como base estudios recientes de los autores en la región, así como otras publicaciones afines. La propuesta presentada se acompaña de figuras explicativas para la representación clara y sencilla de las condiciones geológicas y tectónicas acontecidas con el paso del tiempo.

Los estudios desarrollados abarcan diferentes ramas geológicas como: tectónica, geología estructural, petrología ígnea y sedimentaria, geoquímica, geocronología, paleontología y estratigrafía, y fueron presentados mediante libros, artículos científicos y tesis. Las referencias bibliográficas que fueron la base para esta síntesis son: Aguilar y Denyer (2019); Alvarado y Denyer (2019); Alvarado y Gans (2012); Andjić, Baumgartner-Mora, y Baumgartner (2016); Astorga (1987); Baumgartner y Denyer (2006); David (2005); Denyer y Gazel (2009); DeWever, Azéma, Tournon, y Desmet (1985), Escuder-Viruete, Baumgartner, y CastilloCarrión (2015); Gazel, Denyer, y Baumgartner (2006); Madrigal et al. (2019); Solano, Denyer, Pérez, et al. (2019); y Tournon (1984).

\section{DESCRIPCIÓN LITOESTRATIGRÁFICA}

El extremo noroeste de Costa Rica se encuentra conformado por una amplia variedad de rocas entre ígneas y sedimentarias. Estas rocas han sido afectadas por procesos tectónicos y estructurales complejos que propician su arreglo actual. Un modelo geológico regional simplificado es presentado en la Fig. 1. y en la columna estratigráfica de la Fig. 2.

\section{Ofiolita de Santa Elena}

Complejo Acrecional de Santa Rosa y Brecha Tectónica: De manera general, el Complejo Acrecional de Santa Rosa se encuentra conformado por rocas producto de la acumulación 


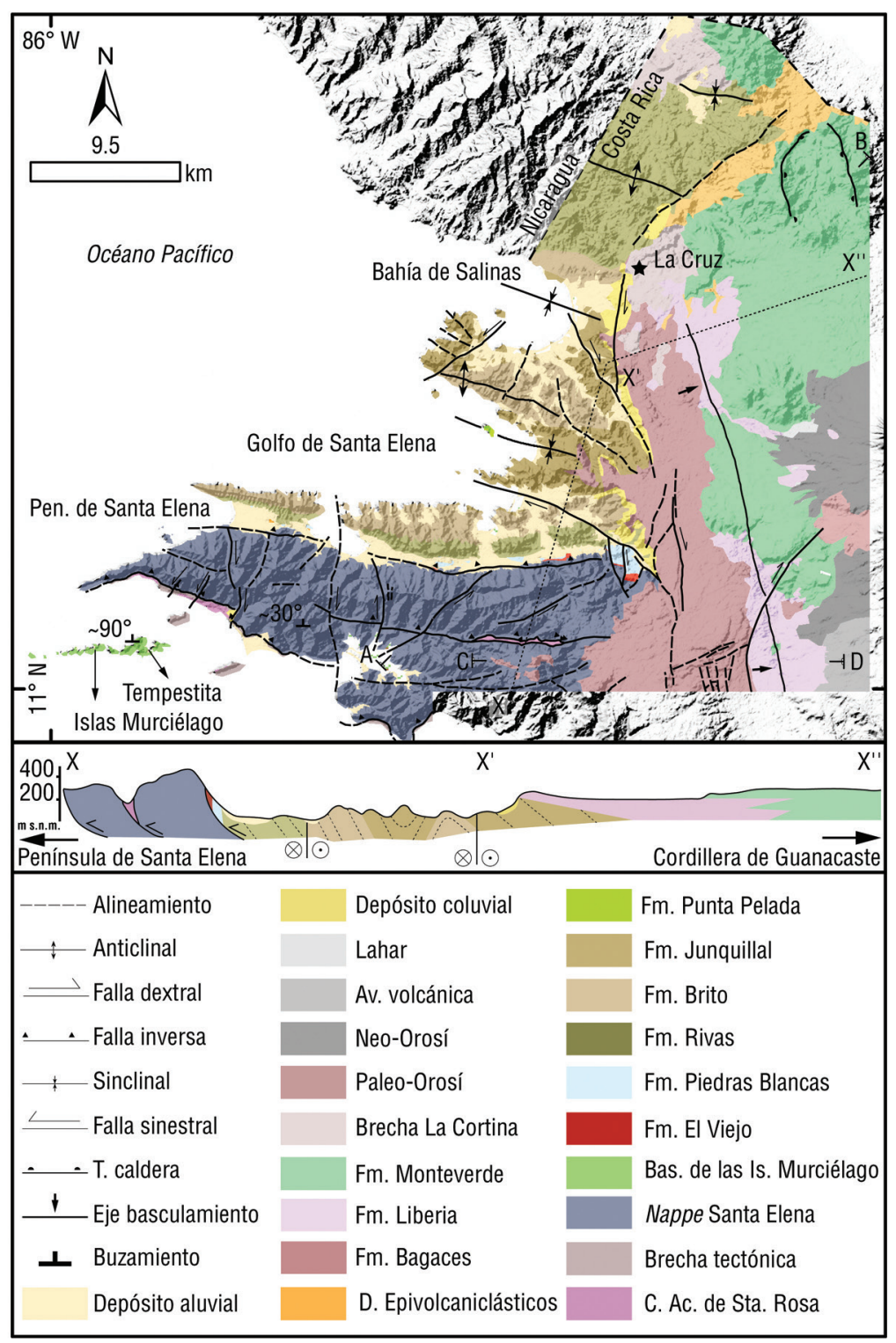

Fig. 1. Modelo geológico actual del noroeste de Costa Rica. Simplificado de Denyer (2019). La topografía y los buzamientos en el perfil geológico fueron exagerados 1.5X. Av.: Avalancha, Fm.: Formación, D.: Depósitos, Bas.: Basaltos, Is.: Islas, C.: Complejo, Ac.: Acrecional.

Fig. 1. Geological model of Northwest Costa Rica. Simplification of Denyer (2019). Topography and dips with an exaggeration at $1.5 \mathrm{X}$ in the geologic section. Av.: Avalanche, Fm.: Formation, D.: Deposits, Bas.: Basalts, Is.: Islands, C.: Complex, Ac.: Accretional.

de sedimentos en el fondo oceánico y su posterior litificación (pelagitas), rocas volcánicas producto de erupciones locales (petit-spot) y brechas polimícticas, es decir con clastos de diverso tipo. Descripciones detalladas de estas rocas fueron presentadas por Baumgartner y Denyer (2006), Denyer y Gazel (2009), Tournon y Bellon (2009), y Madrigal et al. (2019). Respecto a su edad, los depósitos han sido datados de la siguiente manera: radiolaritas 


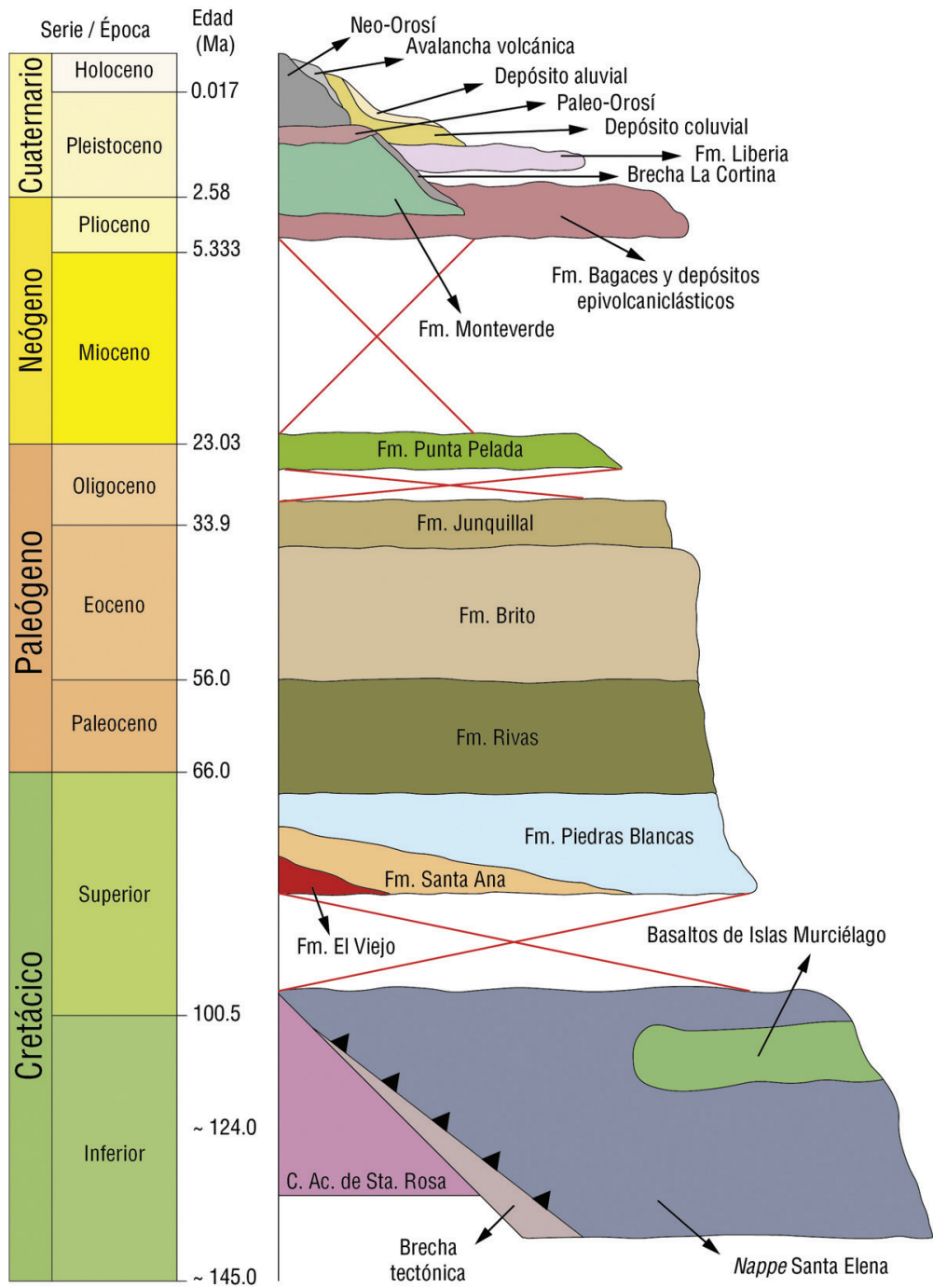

Fig. 2. Columna estratigráfica. La edad del Complejo Acrecional de Santa Rosa corresponde a los sedimentos asociados al periodo de la acreción del Nappe de Santa Elena y no a su rango de edad completo. Fm.: Formación, C.: Complejo, Ac.: Acrecional.

Fig. 2. Stratigraphic column. The Santa Elena Accesonary Complex (Complejo Acrecional de Santa Rosa) age corresponds to sediments associated to the accreation of the Santa Elena Nappe (Nappe de Santa Elena). Fm.: Formation, C.: Complex, Ac.: Accretional.

(Fig. 3D; Jurásico Medio - Cretácico temprano) y varias fases de basaltos alcalinos a nivel de fenocristales (anfíboles) y roca total (177,0 - 104,3 Ma: Jurásico temprano terminal a Cretácico temprano terminal; Baumgartner, Flores, Bandini, Girault, \& Cruz, 2008; Buchs et al., 2013; DeWever et al., 1985; Madrigal et al., 2019; Schmidt-Effing, 1980a; SchmidtEffing, 1980b).

Estas rocas son producto de diferentes procesos. Para la Brecha Tectónica, Madrigal et al. (2019) indican que es producto de la interacción entre el Complejo Acrecional de Santa Rosa y el Nappe de Santa Elena. Por 
otra parte, las rocas del Complejo Acrecional de Santa Rosa presentan varias génesis, como las pelagitas, que son producto de la acumulación de sedimentos en el fondo oceánico que posteriormente tuvieron procesos de metamorfismo de baja temperatura (EscuderViruete \& Baumgartner, 2014). Los basaltos alcalinos son montes submarinos acrecionados (Buchs et al., 2013; Geldmacher, Hoernle, Van Den Bogaard, Hauff, \& Klügel, 2008; Hauff, Hoernle, \& Bogaard, 2000; Tournon, 1994). Estos montes submarinos son relacionados con petit-spots producto de fallamiento normal en la cercanía de una zona de subducción (Hirano, 2011). Estos petit-spots fueron comprobados por Buchs et al. (2013) a partir de su firma geoquímica. Además, Buchs et al. (2013) ahondan en la génesis de los petit-spots para la Ofiolita de Santa Elena, y detallan en que son producto de la fragmentación de la corteza a consecuencia de la reorganización tectónica del basamento del Pacífico y no son cercanos a una zona de subducción.

Nappe de Santa Elena: Es un terreno alóctono de rocas ultramáficas intruidas por rocas máficas que cubren un área de $180 \mathrm{~km}^{2}$ (Fig. 3B, Fig. 3E; Tournon, 1994). Madrigal et al. (2015) establecen un ambiente de formación extensional, según datos geoquímicos y estructurales, donde una parte del manto superior de la Tierra fue exhumado a la superficie terrestre. Esta exhumación probablemente sucedió entre el Aptiano y el Campaniano (Baumgartner \& Denyer, 2006; Denyer \& Gazel, 2009; Pindell, 1988; Tournon, 1994).

El cuerpo principal de este nappe se encuentra conformado de peridotitas serpentinizadas, dunitas, gabros pegmatíticos, doleritas y diques basálticos (Denyer \& Gazel, 2009). Estos son descritos a continuación. (1) Peridotita: corresponde a una secuencia de rocas ultramáficas que incluye las peridotitas serpentinizadas, con lentes de dunitas, ortopiroxenitas y cromitas (Denyer \& Gazel, 2009; Escuder-Viruete et al., 2015; Gazel et al., 2006; Tournon, 1994; Tournon \& Bellon, 2009; Zaccarini et al., 2011). Las peridotitas son rocas comunes en el manto terrestre y no en la corteza, y su emplazamiento en superficie está dado por mecanismos litosféricos complejos y anómalos. Este grupo principal de rocas ultramáficas se encuentran intruidas por dos fases: diques de gabro pegmatítico y diques de dolerita. Las fases intrusivas se caracterizan por ser magmas que cruzan y cortan rocas preexistentes; en este caso, magmas que atraviesan el cuerpo principal de peridotita. (2) Diques de gabro pegmatítico: se emplazaron en el momento en que las peridotitas se estaban solidificando, es decir son eventos sincrónicos; sin embargo, las peridotitas son ligeramente más antiguas (Gazel et al., 2006). Han sido descritos a profundidad por Gazel et al. (2006); Tournon (1994); y Tournon y Bellon (2009). (3) Diques de dolerita: son una fase intrusiva posterior, es decir se emplazaron posterior a la litificación de los gabros pegmatíticos y las peridotitas (Fig. 3B; Gazel et al., 2006). Denyer y Gazel (2009); Gazel et al. (2006); Madrigal et al. (2015); Tournon (1994); Tournon \& Bellon (2009) presentan descripciones geológicas de estos diques, y fueron datados por Madrigal et al. (2015) con un promedio de $121 \mathrm{Ma}$.

Complejo Ígneo Estratificado de Bahía Nancite: El complejo se encuentra en bahía Nancite y está constituido por dos generaciones de diques: doleritas y basaltos olivínicos diferenciados por su contenido mineralógico (Arias, 2002; Gazel et al., 2006; Tournon, 1994). Los basaltos y plagiogranitos fueron descritos por Arias (2002), Denyer y Gazel (2009), Gazel et al., (2006), Madrigal et al. (2019), y Tournon (1994). Los gabros de este complejo fueron datados por Hauff et al. (2000) en $124 \pm 4 \mathrm{Ma}$ mediante ${ }^{40} \mathrm{Ar} /{ }^{39} \mathrm{Ar}$.

Basaltos de las Islas Murciélago: Son basaltos con una estructura predominantemente en almohadilla que es indicativa de efusión y enfriamiento bajo el nivel del mar, por lo que estos basaltos representan los depósitos de erupciones volcánicas submarinas (Fig. 3a, Fig. 3C). Son basaltos y traquibasaltos descritos por Gazel et al. (2006), Madrigal et al. (2015), Tournon (1994), y Tournon y Bellon (2009) y su edad es variable entre $109 \pm 2$ y $113 \pm 3$ Ma mediante ${ }^{40} \mathrm{Ar} /{ }^{39} \mathrm{Ar}$ (Hauff et al., 

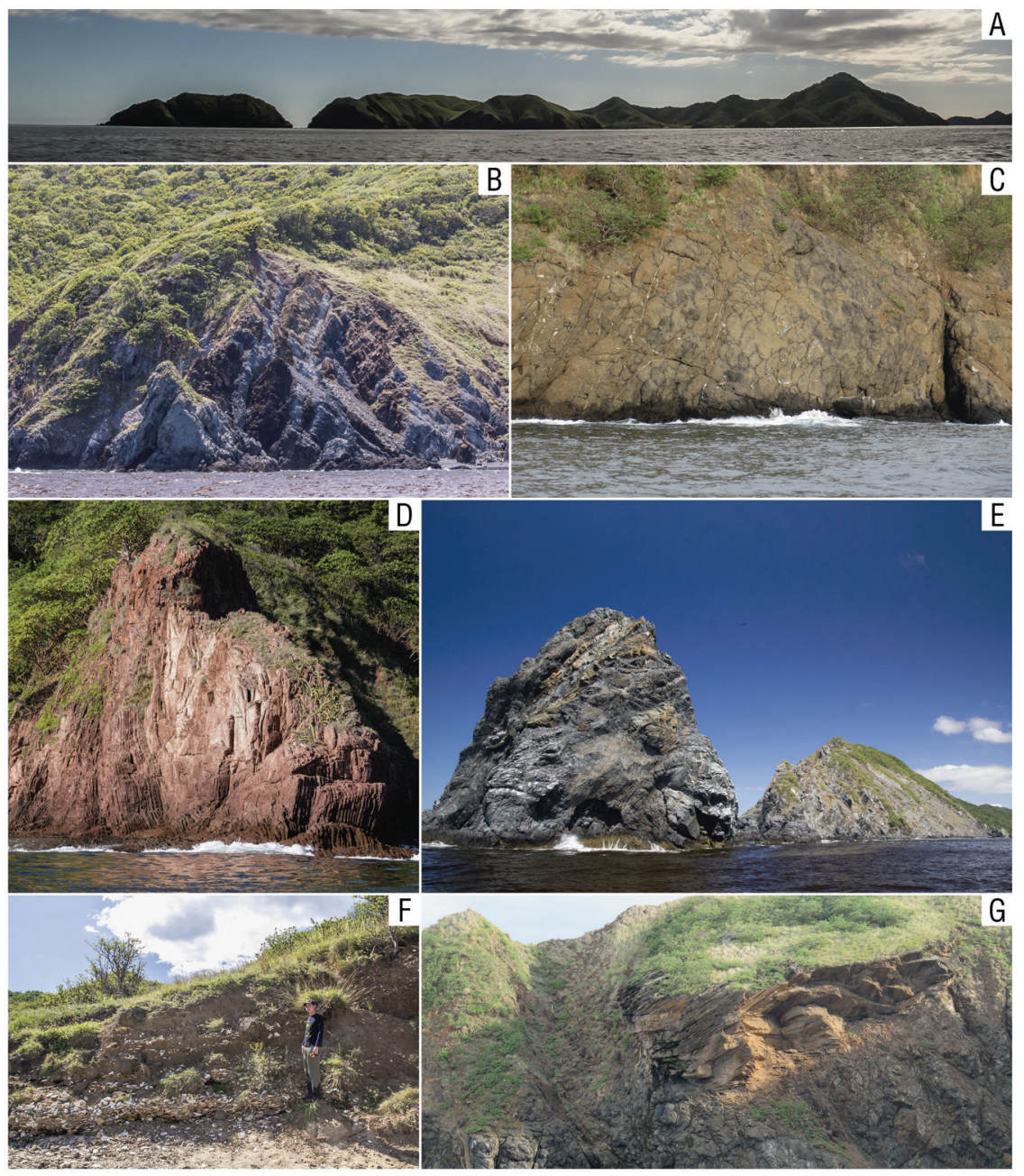

Fig. 3. Litologías características del área de estudio. A. Vista panorámica de las Islas Murciélago. B. y E. Intrusiones de dolerita en peridotitas. C. Basaltos en almohadilla de las Islas Murciélago. D. Radiolaritas en estratos verticales del Complejo Acrecional de Santa Rosa. F. Depósitos de tempestitas. G. Duna fósil.

Fig. 3. Characteristic lithologies of the studied area. A. Panoramic view of Murciélago Islands. B. and E. Doleritic intrusions on peridotites. C. Murciélago Islands pillow lavas. D. Vertical strata of radiolarites of the Accretionary Complex of Santa Rosa. F. Tempestites deposits. G. Fossil dune.

2000; Madrigal, Gazel, Flores, Bizimis, \& Jicha, 2016).

\section{Rocas sedimentarias}

Formación El Viejo: Su principal litología corresponde a calizas producto de la litificación de arrecifes coralinos de edad Campaniano (Aguilar \& Denyer, 2019; Denyer, Aguilar, \& Montero, 2014; Malavassi, 1961; Pons, Vicens,
\& Schmidt-Effing, 2016; Schmidt-Effing, 1974). Estos arrecifes fueron gobernados por bioconstrucciones de rudistas y nerineas, mismos que se extinguieron a finales del Cretácico (Fig. 4; Aguilar, 1990). Schmidt-Effing (1974) caracteriza su ambiente de formación como arrecifes coralinos con aguas claras en movimiento, a una temperatura mínima de 24 ${ }^{\circ} \mathrm{C}$ y una profundidad no mayor a los $70 \mathrm{~m}$. Algunos estudios importantes sobre estas rocas 
son los de Andjić et al. (2016); Azéma et al. (1985); Baumgartner et al. (1984); Bourgois et al. (1984); Calvo (1987); Flores, Denyer, y Aguilar (2003); y Hoffstetter, Dengo, y Weyl (1960).

Formación Santa Ana: Son depósitos interpretados como flujos de escombros (debris flow) y brechas de talud emplazados en los márgenes de plataformas carbonatadas (arrecifes coralinos de la Formación El Viejo) a consecuencia de retrabajo y periodos de levantamiento tectónico (Fig. 4; Calvo, 1987; Jaccard, Münster, Baumgartner, BaumgartnerMora, \& Denyer, 2001). Según asociaciones paleontológicas su edad varía del Campaniano tardío al Maastrichtiano (Aguilar \& Denyer, 2002; Baumgartner-Mora \& Denyer, 2002; Flores et al., 2003; Jaccard et al., 2001). En esta formación se han descrito conglomerados, brechas y areniscas con detritos calcáreos, sedimentarios e ígneos; además, de lutitas rojizas y calizas rojas (Aguilar \& Denyer, 2019; Andjić et al., 2016; Denyer et al., 2014; Flores et al., 2003; Hoffstetter et al., 1960). Algunas de estas litologías presentan bioturbación y otras son interpretadas como pelagitas y eventitas (Denyer et al., 2014). La distribución espacial de esta formación no se visualiza en el mapa geológico (Fig. 1), debido a efectos de la escala de trabajo.

Formación Piedras Blancas: Son rocas resultado de la litificación de material biogénico y granos de tamaño limo y arcilla en el fondo oceánico y márgenes continentales, es decir sedimentación hemipelágica y pelágica (Aguilar \& Denyer, 2019; Azéma et al., 1985; Baumgartner et al., 1984; Calvo, 1987; Flores et al., 2003). Su edad está delimitada entre el Campaniano Superior y el Maastrichtiano Inferior (Aguilar \& Denyer, 2019). Las litologías que la componen son calcilutitas, lodolitas con vetas de calcita, areniscas, lutitas, calizas silíceas pelágicas y pedernales (Aguilar \& Denyer, 2019; Andjić et al., 2016; Astorga, 1987; Calvo, 1987; Flores et al., 2003).

Formación Rivas: En la Formación Rivas se incluyen depósitos de deslizamientos y corrientes de turbidez depositadas en el talud continental (Fig. 4; Aguilar \& Denyer, 2019; Andjić et al., 2016; Astorga, 1987; Baumgartner et al., 1984). Previo a su litificación, estos depósitos fueron afectados por deformación sinsedimentaria que se expresa en forma de slumps (Aguilar \& Denyer, 2019). Sus rocas corresponden a areniscas (con meteorización esferoidal), lutitas, calcilutitas, lutitas volcaniclásticas, areniscas tobáceas, calizas hemipelágicas, areniscas conglomerádicas y conglomerados (Andjić et al., 2016; Baumgartner et al., 1984; Zoppis de Bracci \& Del Giudice, 1958). Su edad varía entre el Cretácico Superior y el Paleoceno (Andjić et al., 2016; Auer, 1942).

Formación Brito: Estas rocas corresponden a turbiditas al igual que los depósitos de la Formación Rivas (Fig. 4, Fig. 5A y Fig. 5B); sin embargo, se encuentran interrumpidas por horizontes de material biogénico y granos de tamaños muy pequeños o hemipelagitas (Andjić et al., 2016; Astorga, 1987). Además, los depósitos superiores evidencian procesos de somerización (Aguilar \& Denyer, 2019); es decir muestran la presencia de rocas formadas a poca profundidad bajo el nivel del mar. Respecto a su edad se ubican entre el Eoceno temprano y el Oligoceno temprano (Andjić et al., 2016; Dengo, 1962; Hayes, 1899; Ranero et al., 2000). Entre sus litologías se han reconocido areniscas (arcosas líticas y wackas tobáceas), lutitas, calizas (en su mayoría como lentes), conglomerados, brechas, lodolitas y limolitas (Aguilar \& Denyer, 2019; Andjić et al., 2016; Dengo, 1962; Hoffstetter \& Zoppis de Bracci, 1960).

Formación Junquillal: Aguilar \& Denyer (2019) asocian estos depósitos con tempestitas. Las tempestitas o tormentitas son depósitos formados bajo condiciones de tormentas en zonas marino-someras, posiblemente en etapas de descenso del nivel del mar (Fig. 4, Fig. 5C; Aguilar, Denyer, \& Arredondo, 2020). Su rango de edad se encuentra entre el Paleoceno Superior - Eoceno Inferior al Oligoceno Inferior (Aguilar \& Denyer, 2019; Andjić et al., 2016; Malavassi, 1961; Zamora, Méndez, Barahona, \& Sjöbohm, 2004). Las rocas que 


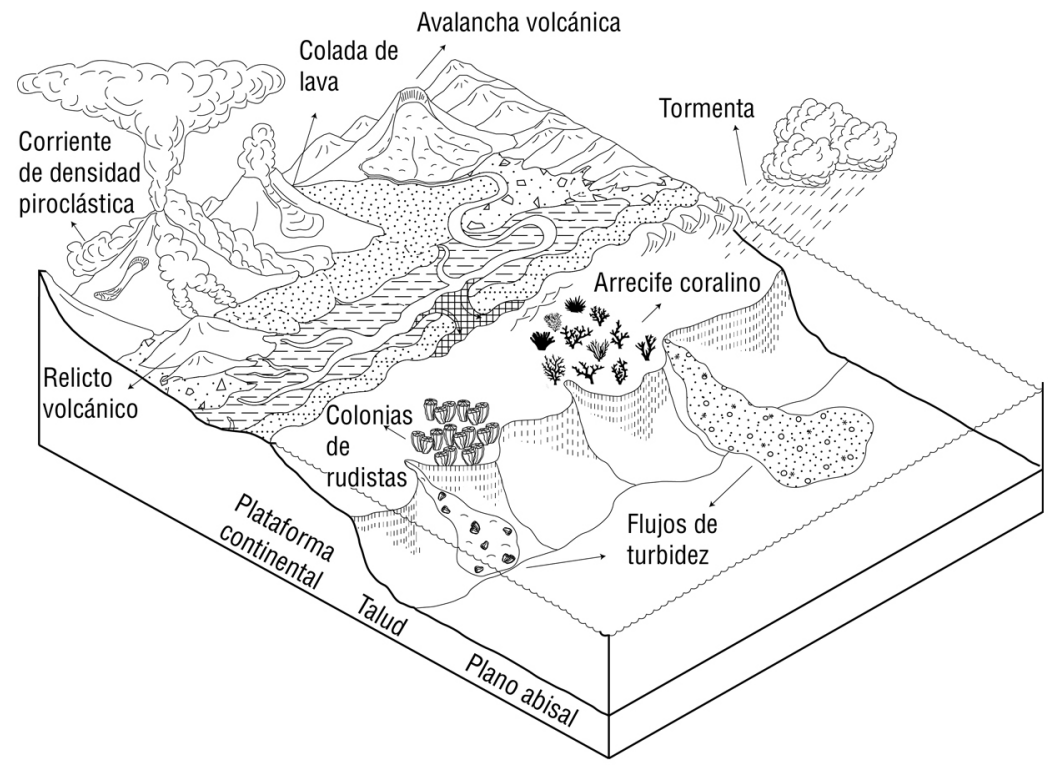

Fig. 4. Diagrama esquemático de ambientes de formación de rocas ígneas y sedimentarias en un arco de islas como el documentado en el noroeste de Costa Rica del Cretácico tardío al Cuaternario.

Fig. 4. Schematic diagram of the environments of formation of igneous and sedimenatry rocks in the northwest of Costa Rica from Late Cretaceous to the Quaternary.

conforman esta formación son conglomerados, areniscas finas a gruesas (arenitas y arcosas líticas), lutitas (lodolitas) y calcirruditas (Baumgartner et al., 1984; Andjić et al., 2016; Aguilar \& Denyer, 2019).

Formación Punta Pelada: Andjić et al. (2016) identifican una zona genética desde prearrecifal - plataforma a arrecife coralino (Fig. 5D). Por otra parte, Aguilar \& Cortés (2001) relacionan estas rocas con ambientes de poca profundidad con influencia de corrientes fuertes, un aporte terrígeno continuo, cambios frecuentes de energía en el medio y cambios en el nivel del mar (Fig. 4). Litológicamente, está conformada por calizas biodetríticas, areniscas calcáreas, conglomerados, calizas masivas y calizas brechosas, todos con bioconstrucciones de corales y algas (Aguilar \& Cortés, 2001; Aguilar \& Denyer, 2019; Andjić et al., 2016; Calvo, 1987). La edad de estas rocas ha sido estimada para el Oligoceno según asociaciones paleontológicas (Andjić et al., 2016; Hoffstetter \& Zoppis de Bracci, 1960).

\section{Eventos extrusivos de tipo explosivo $y$ rocas asociadas}

Los eventos volcánicos extrusivos de tipo explosivo se refieren a aquellos que generan depósitos piroclásticos producto de erupciones volcánicas ricas en ceniza, pómez y fragmentos de roca (Fig. 4). Estos tipos de erupciones son a consecuencia del colapso de columnas de tefra, explosiones laterales o el colapso de edificios volcánicos, domos y coladas de lava (Branney \& Kokeelar, 2002). Los depósitos explosivos reconocidos en esta investigación corresponden a la Meseta Volcánica de Santa Rosa, en su mayoría conformada por la Formación Bagaces, y el abanico formado por la Formación Liberia (Dengo, 1962). Dóndoli (1950) es el primero en mencionar las formaciones Bagaces y Liberia como toba gris y toba blanca respectivamente. Algunas consideraciones petrológicas y volumétricas fueron expuestas por David (2005); Deering, Vogel, Patino, y Alvarado, (2007); Gillot, Chiesa, y Alvarado (1994); 


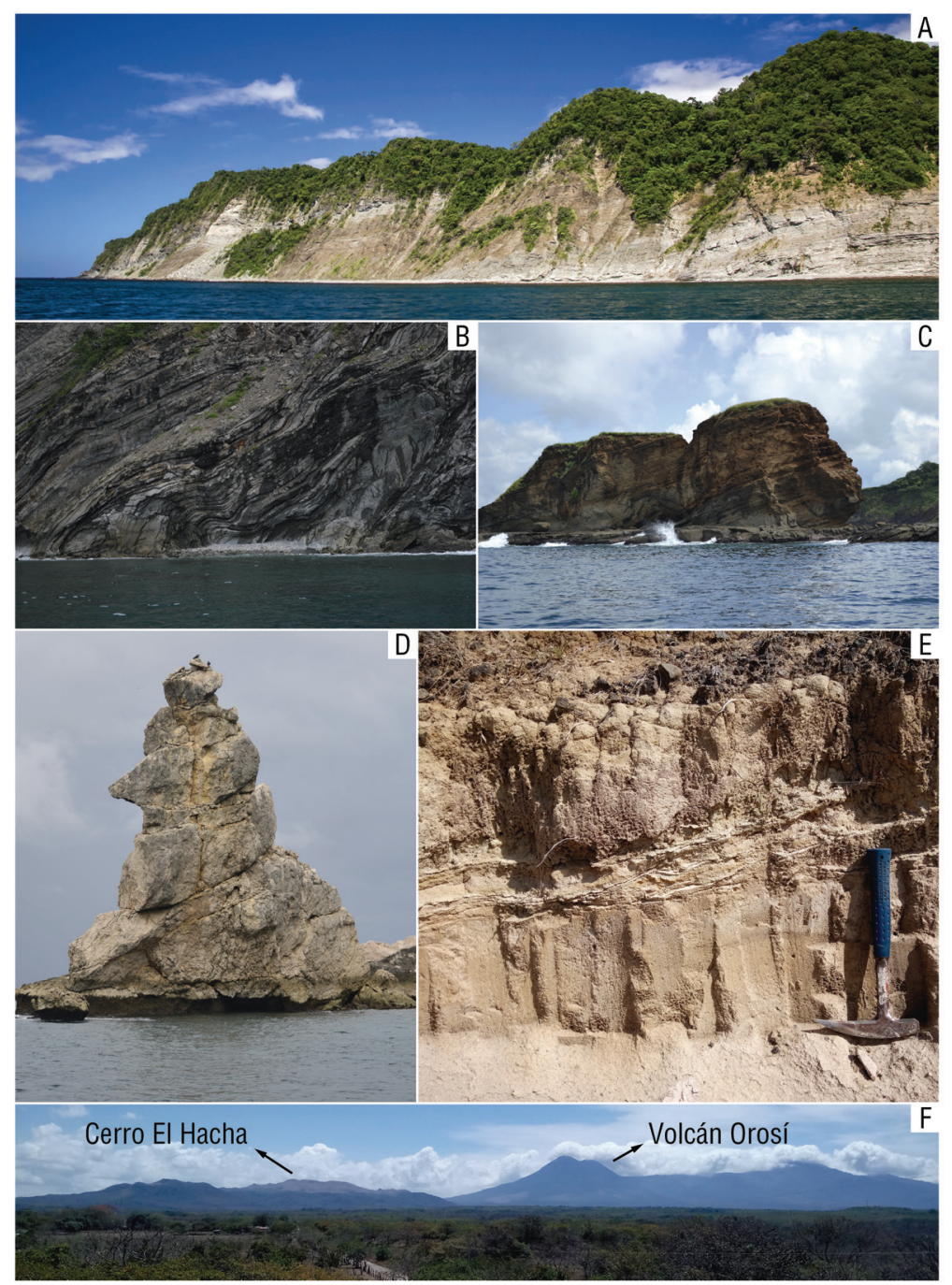

Fig. 5. Litologías características del área de estudio. A y B. Estratos de la Formación Brito. C. Estratos de la Formación Junquillal. D. Rocas de la Formación Punta Pelada. E. Depósitos de la Formación Bagaces. F. Vista al cerro El Hacha y el volcán Orosí desde la Meseta Volcánica de Santa Rosa.

Fig. 5. Characteristic lithologies of the studied area. A, B. Strata of the Brito Formation. C. Junquillal Formation strata. D. Punta Pelada Formation rocks. E. Bagaces Formation deposits. F. Panoramic view with El Hacha mount and Orosí volcano from the Meseta Volcánica de Santa Rosa.

Tournon (1984); Vogel, Patino, Alvarado, \& Gans (2004); y Vogel et al. (2006).

Formación Bagaces: Denominada formalmente por Dengo (1962) como Formación Bagaces, la propuesta estratigráfica más reciente para esta formación es de Barrantes (2018), Alvarado y Denyer (2019) y de Solano, Denyer, Pérez, et al. (2019). Es común que estos depósitos ignimbríticos andesíticos a riolíticos presenten niveles vitrofíricos, desgasificación, diaclasamiento, lajeamiento y disyunción columnar, además sus clastos principales son de pómez, clinopiroxeno y ortopiroxeno (Fig. 5E; Aiazzi, Fiorletta, Civelli, Chiesa, \& Alvarado, 2004; Alvarado \& Denyer, 2019; Barrantes, 2018; Bohnenberger, 1968; Civelli et al., 2005; 
David, 2005; Dengo, 1962; Gillot et al., 1994; Herrera \& Vargas, 2012; Kempter, 1997; Molina, Martí, Aguirre, Vega, \& Chavarría, 2014; Semm, 2005; Setzer, 1994; Solano, Denyer, \& Pérez, 2019; Szymanski, Patino, Vogel, \& Alvarado, 2013; Tournon, 1984; Zamora et al., 2004). Alvarado y Gans (2012) mencionan un rango de edades en los depósitos piroclásticos entre 4.87 y 2 Ma.

Formación Liberia: Comprende las rocas piroclásticas con edades entre 1.81 y $0.6 \mathrm{Ma}$ nombradas de base a techo como: (1) Capa Verde, Capa Santa Fe y Toba Santa Fe, (2) Toba Río Liberia, (3) Toba Salitral, (4) Toba Buena Vista y (5) Toba La Ese (Alvarado \& Denyer, 2019; Alvarado \& Gans, 2012; Chiesa, Civelli, Gillot, Mora, \& Alvarado, 1992; Deering et al., 2007; Gillot et al., 1994). Petrográficamente, son riolitas con cristaloclastos de cuarzo, biotita y anfíbol (Alvarado \& Denyer, 2019; Bohnenberger, 1968; Chiesa et al., 1992; Deering et al., 2007; Deering, Vogel, Patino, Szymanski, \& Alvarado, 2012; Dengo, 1962; Hallinan \& Brown, 1995; Kempter, 1997; Zamora et al., 2004; Molina et al., 2014).

Depósitos epivolcaniclásticos: Alvarado \& Denyer (2019) los identifican como depósitos fluviales, aluviales y laháricos de granulometría variada y de tipo sinvolcánico; es decir, corresponden a la erosión de las litologías de origen volcánico. Barrantes (2018) fuera del área de estudio los reconoce y caracteriza como depósitos fluviales.

\section{Rocas efusivas y eventos relacionados}

Formación Monteverde: Definida como formación por Chaves y Sáenz (1974). Se compone de rocas a consecuencia de erupciones volcánicas efusivas, es decir coladas de lava por origen central y fisural (Fig. 4; Aiazzi et al., 2004; Chaves \& Sáenz, 1974; Gillot et al., 1994). Esta actividad volcánica fue entre hace 2.18 y $1.13 \mathrm{Ma}$ (Alvarado \& Gans, 2012). Algunos centros eruptivos cercanos al área de estudio son el cerro El Hacha, Peña Bruja y Alto Filipinas (Fig. 5F; Alvarado \& Denyer, 2019). Las rocas de esta formación son en su mayoría andesitas (Alvarado \& Denyer, 2019;
Chiesa, Alvarado, Pecchio, Corella, \& Zanchi, 1994; Cigolini \& Chaves, 1986; Kussmaul, Tournon, \& Alvarado, 1994).

Brecha La Cortina: Es un depósito de avalancha de escombros volcánicos (Fig. 4; Alvarado \& Denyer, 2019). Estos depósitos suelen estar asociados con grandes deslizamientos. En este caso en específico, corresponde a un megadeslizamiento asociado al cerro El Hacha o una estructura caldérica cercana al noreste del centro poblacional de La Cruz.; litológicamente, se trata de brechas polimícticas y polimodales, con una edad de 1.3 Ma (Alvarado \& Denyer, 2019).

Lacustre Loma Camastro: Se reconocen como sedimentos epivolcaniclásticos intercalados con diatomitas (Alvarado \& Denyer, 2019; Gómez, 1992; Zamora et al., 2004). Su génesis se refiere a paleolagos y fluviolacustres producto de acumulaciones de agua, limitadas por barreras físicas a consecuencia del vulcanismo con edad entre 1.48 y 1.1 Ma (Alvarado \& Denyer, 2019; Gamboa, 2013; Zamora et al., 2004). Esta unidad no está representada en el mapa geológico (Fig. 1), debido a que la escala de trabajo no permite su visualización.

Paleo y Neo Orosí: Es un conjunto de edificios volcánicos erosionados compuestos por el volcán Orosí, el cerro Orosilito, cerro Pedregal y el cerro Cacao (Fig. 5F; Alvarado, 1984; Alvarado \& Denyer, 2019; Chiesa et al., 1994). Alvarado y Gans (2012) resumen la historia geológica del macizo: (1) vulcanismo Paleo-Orosí, representado por los restos del volcán Orosilito; (2) Neo vulcanismo con los conos Orosí y Cacao; (3) Colapsos sectoriales producto de la erosión de los conos principales; y (4) reactivación con las coladas de lava en el Cacao. Se compone de andesitas, andesitas basálticas, basaltos, variedad de rocas piroclásticas y epiclásticas (Alvarado, 1984; Chiesa et al., 1994; Kussmaul et al., 1994; Tournon, 1984; Zamora et al., 2004).

\section{Depósitos recientes}

En este apartado se incluyen depósitos con sedimentación activa y de reciente 
litificación, es decir de edad Pleistoceno Superior - Holoceno.

Depósitos Laháricos y Avalanchas Volcánicas: Los depósitos laháricos y de avalancha volcánica presentan una génesis asociada con la erosión y el efecto de la gravedad de los edificios volcánicos Rincón de la Vieja y Orosí - Cacao, mediadas por disparadores como sismos, actividad volcánica o agentes metereológicos (Fig. 4). En los depósitos de avalancha volcánica es común reconocer hummockys e imbricación en los lahares (Alvarado, Vega, Chaves, \& Vásquez, 2004; Zamora et al., 2004). Alvarado y Denyer (2019) estiman una edad entre Pleistoceno Superior y Holoceno temprano. Algunas descripciones representativas son las de Kempter (1997).

Dunas Fósiles: Se hace diferencia de esta subunidad respecto a las demás porque se trata de arenas litificadas ubicadas en las islas Murciélago (Fig. 3G). Su proceso de litificación se produjo por splash marino y disolución parcial de los fragmentos bioclásticos (Aguilar \& Denyer, 2019). Estas arenas litificadas presentan estratificación cruzada con ángulos de hasta $50^{\circ}$ y tienen cementación por carbonato de calcio (Denyer et al., 2006). Según dataciones de ${ }^{14} \mathrm{C}$ la edad máxima de las dunas varía entre 16 y 17 ka en función del evento paleo-climático Heinrich 1 con direcciones de viento del NE al SW (Denyer, Cortés, \& Cárdenes, 2005).

Tempestitas: Son depósitos con evidencias de transporte y depositación a consecuencia de eventos ciclónicos con una edad aproximada de hace $4.3 \mathrm{ka}$ (Aguilar et al., 2020). Su ubicación se detalla en el mapa geológico (Fig. 1) y la figura $3 \mathrm{~F}$ muestra una foto del afloramiento.

Depósitos no Consolidados: Estos depósitos corresponden a acumulaciones de sedimentos no litificados que se mantienen con sedimentación activa al día de hoy. En esta unidad se contemplan los depósitos aluviales, dunas activas, humedales, depósitos coluviales y depósitos de playa (Fig. 4).

\section{BIOLOGÍA Y GEODIVERSIDAD}

En el Área de Conservación Guanacaste se encuentran gran cantidad de paisajes extraordinarios, ahí empieza una experiencia geológica y biológica que da paso a confirmar las interrelaciones entre la Geología y la Biología. Definitivamente, la geología influencia, en parte, a las características biológicas de una región, lo que es un factor determinante de hábitats y especies, principalmente en cuanto a la parte botánica (Cottle, 2004). También existe una retroalimentación de los aspectos biológicos hacia aquellos nichos geológicos, que son influenciados por la erosión y meteorización de plantas, así como la presencia de animales en una región.

El término geodiversidad se puede definir como la diversidad geológica de una región, entendida como la variedad de rasgos geológicos identificados tras considerar su distribución y frecuencia, así como estos ilustran la evolución e historia geológica del territorio en cuestión (Caravilla, Durán, \& López-Martínez, 2008). Es así como se considera que el sustrato, constituido primero por la roca y después por el suelo resultante de la meteorización y erosión determina parcialmente la vegetación.

La diversidad de formaciones geológicas define el paisaje y así los diferentes bosques que se desarrollan; porque los árboles, las palmas, y en general, muchas plantas tienen sus preferencias geológicas, incluso desde lejos un buen observador puede distinguir estas diferencias por la composición de especies mediante rasgos como tamaño de árboles, densidad de bosque o zonas con o sin pasto. Por ejemplo, las rocas calcáreas o sedimentos marinos, de las formaciones Rivas, Brito y Junquillal son el sustrato característico de bosques con una buena densidad de guayacán real (Guaiacum sanctum) de la familia Zygophyllaceae (Barwick \& Schans, 2004). Lo mismo sucede con la palma Attalea rostrata (Standley \& Steyermark, 1946) de una apariencia grande y masiva con palmas u hojas tan grandes como $3.5 \mathrm{~m}$.

Si se encuentra un rodal de roble encino (Quercus oleoides) (Gallagher, 2020), muy probablemente se puede asegurar que están creciendo sobre un sustrato constituido por rocas tipo ignimbritas o suelos cuya base son 
ignimbritas. De la misma forma, se puede asegurar que si la densidad de cornizuelo (Vachellia collinsi o Vachellia cornigera; Boza, 2019) es muy alta, el suelo es de origen ignimbrítico. Esto resulta visible en las zonas a donde afloran las formaciones Bagaces o Liberia para el área de estudio.

Las rocas provenientes del manto, comúnmente denominadas serpentinitas, que en este trabajo corresponden con el Nappe de Santa Elena, son un elemento sobresaliente, pues al provenir de grandes profundidades (normalmente más de $40 \mathrm{~km}$ ) su composición química difiere sustancialmente de aquellas rocas formadas en la superficie terrestre. Entonces, por su proveniencia no son de un carácter "amigable" con la mayoría de la biota. Estas rocas tienen una composición en la que el hierro y el magnesio son muy altos relativamente en comparación con el sílice, el calcio es muy bajo con respecto al magnesio, así como tienen altos niveles de níquel, cromo, manganeso y cobalto. Kruckeberg (2002) sugiere un alto contraste de vegetación entre suelos provenientes de la meteorización de serpentinitas y aquellos que no lo son, además, este autor señala la existencia de especies endémicas en suelos de afinidad serpentinitica. El tipo de vegetación sobre las serpentinitas de la península de Santa Elena es excepcionalmente baja y espinosa. Es destacable, por ejemplo, que sobre estas rocas del manto terrestre se encuentran cactus, como el Melocactus curvispinus (CONABIO, 2020; Taylor, 1991); o bien, un arbusto deciduo pequeño (1.5-4 m) como el Bursera schlechtendalii (Espinoza, Guadamuz, Pérez, Chavarría, \& Masís, 2000).

\section{GEOLOGÍA ESTRUCTURAL Y TECTÓNICA}

Este apartado tratará tres ámbitos importantes para la descripción geológica estructural del área de estudio, que son los elementos estructurales, las zonas morfotectónicas y las etapas compresivas que han tomado lugar sobre las rocas estudiadas. Los elementos estructurales relevantes para el área de estudio son
(Fig. 1): (1) La falla Murciélago con una traza este - oeste y que se encuentra parcialmente cubierta (Denyer, Gazel, Aguilar, Madrigal, \& Chavarría, 2019). (2) El tren de pliegues de Santa Elena, clasificado como disarmónico asimétrico por sobrecorrimiento y compuesto por el anticlinal Montes de Oro, el sinclinal de Salinas, el anticlinal Descartes y el sinclinal Junquillal (Denyer, Vargas, Lücke, \& Solano, 2019). (3) El eje de basculamiento de tobas con rumbo $\mathrm{N} 14^{\circ} \mathrm{W}$ e inclinaciones de entre 0.8 y $1^{\circ}$ hacia el E (Denyer, Vargas, et al., 2019). (4) El Nappe de Santa Elena, que evidencia un cabalgamiento producto de una falla inversa con un basculamiento de hasta $30^{\circ}$ al norte y una ventana tectónica.

La morfología del área de estudio se puede subdividir en cinco zonas morfotectónicas: (1) Nappe, (2) tren de pliegues, (3) plataforma ignimbrítica, (4) relictos volcánicos y (5) cordillera volcánica de Guanacaste (Fig. 6).

La zona denominada Nappe corresponde con la sección que comprende a la Ofiolita de Santa Elena. Es una zona escarpada y afectada intensamente por procesos erosivos. Su altura máxima es el cerro El Inglés de 2525 m s.n.m. y presenta una leve inclinación hacia el norte.

El tren de pliegues (secuencia de rocas deformadas de manera ondulante que varían entre sinclinales y anticlinales) es la segunda zona y afecta geológicamente a las rocas sedimentarias (Cretácico Superior - Paleógeno) del área de estudio. Estas rocas fueron afectadas por una compresión que las deformó hasta el punto de poder visualizar una estructura sinuosa en los depósitos. La deformación provoca que estos terrenos tengan una gran variación en su elevación como se muestra en la Fig. 6A con diferencias de elevación de hasta $\sim 310 \mathrm{~m}$.

La tercera zona es la plataforma ignimbrítica. Se reconoce porque es una planicie extendida hacia el este del área de estudio. La planicie alcanza los $300 \mathrm{~m}$ de altura y es a consecuencia del emplazamiento de ignimbritas. En la Fig. 6A y Fig. 6B se muestra cómo esta planicie presenta una leve inclinación hacia el este y como debajo de esta se encuentran rocas sedimentarias asociadas al tren de pliegues. 


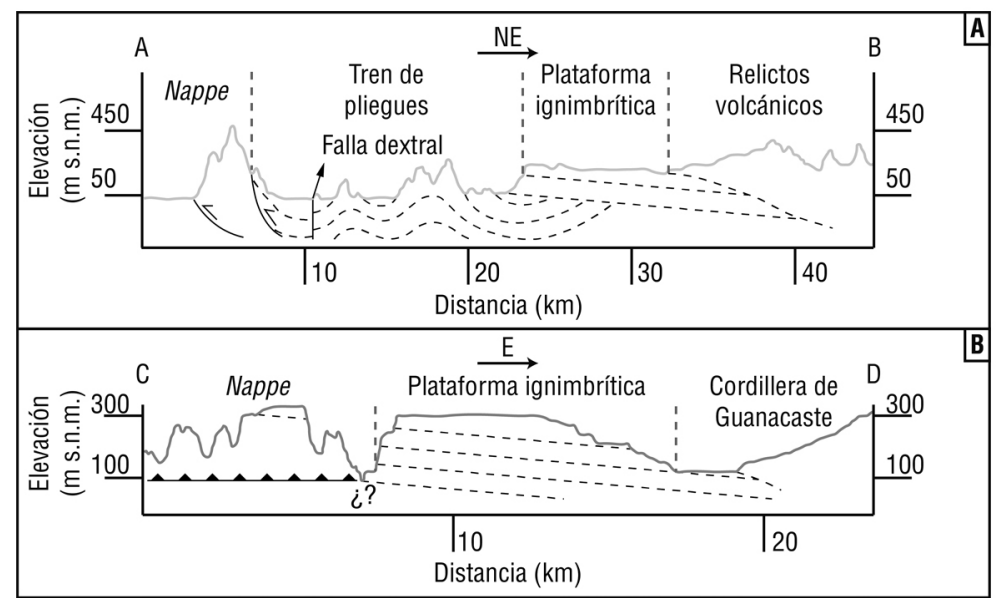

Fig. 6. Perfiles topográficos. A. Perfil con dirección suroeste-noreste. B. Perfil con dirección oeste-este. Exageración vertical a 2.0X. La ubicación de los perfiles se muestra en la Fig. 1. Las líneas punteadas indican la orientación y disposición de las capas de roca.

Fig. 6. Topographic sections. A. Southwest-Northeast profile. B. West-East profile. Vertical exaggeration is 2.0X. Location of the topographic sections is shown in Fig. 1. Dotted lines indicate orientation and disposition of rock beds.

La zona de relictos volcánicos se ubica al noreste del área de estudio. Esta morfología se ha producido en las rocas efusivas más antiguas del área de estudio, es decir, volcanes extintos de hasta 2.18 Ma (Alvarado \& Gans, 2012) afectados por fuertes tasas de erosión. Por tanto, su elevación general se encuentra por debajo de los $450 \mathrm{~m}$ s.n.m. y poseen fuertes pendientes (Fig. 6B).

La zona morfotectónica de las laderas de la cordillera volcánica de Guanacaste, en específico del macizo Orosí - Cacao, se identifica en el extremo SE del área de estudio y se abarca parcialmente. Según la figura 6B alcanza elevaciones de $300 \mathrm{~m}$ s.n.m., pero estas llegan a ser mucho mayores y sus pendientes no presentan cambios abruptos.
Para el extremo noroeste de Costa Rica se han reconocido varias fases tectónicas compresivas con las siguientes edades: (1) Cretácico Inferior, (2) Cretácico Superior temprano Campaniano temprano, (3) Eoceno Superior - Mioceno y (4) Cuaternario (Fig. 7).

Cretácico Inferior (Barremiano - Aptiano): su origen está inferido por la presencia de un margen convergente entre las placas Farallón y Norteamericana, en el cual interactuó la Gran Provincia Ígnea del Caribe (Caribbean Large Igneous Province: Astorga et al., 1991; Azéma et al., 1985; Baumgartner \& Denyer, 2006; Escuder-Viruete \& Baumgartner, 2014; Escuder-Viruete et al., 2015; Escuder-Viruete et al., 2019; Gursky, 1988; Kuijpers, 1980). Una placa tectónica es un fragmento de la corteza

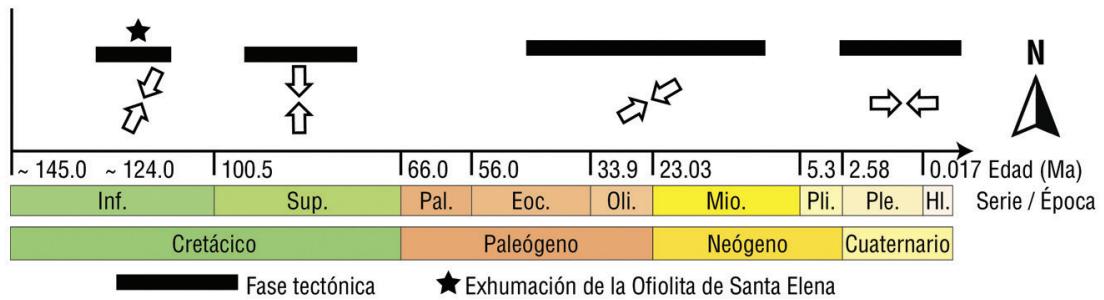

Fig. 7. Fases tectónicas compresivas. Las flechas indican las orientaciones reales de las fases tectónicas.

Fig. 7. Compressive tectonic phases. Arrows indicate the real orientation of the tectonic phases. 
que se mueve a consecuencia de las corrientes de convección en el manto superior. A partir de esta interacción entre placas, se desarrolló un efecto compresivo con dirección NNE-SSW (Meschede \& Frisk, 1998). Escuder-Viruete \& Baumgartner (2014) proponen una edad Barremiano - Aptiano. Algunos eventos específicos datados fueron la acreción de los petit-spots durante el Albiano y la exhumación de la Ofiolita de Santa Elena hace 124 Ma durante el Aptiano Inferior (Escuder-Viruete \& Baumgartner, 2014; Escuder-Viruete et al., 2015). El principal producto de esta deformación se encuentra en los depósitos más antiguos del Complejo Acrecional de Santa Rosa (Baumgartner \& Denyer, 2006).

Cretácico Superior temprano - Campaniano temprano: se asocia con un cambio global en los vectores de movimiento de las placas tectónicas (Astorga et al., 1991; Gursky, 1988; Meschede, Frisch, \& Sick, 1988). Pindell et al. (1988) atribuyen estos esfuerzos a la convergencia entre las placas Farallón y Norteamericana. Tournon (1994) indica una dirección N-S de los esfuerzos según estrías de falla, y Meschede y Frisk (1994) relacionan esta deformación con el Escarpe de Hess. El sobrecorrimiento de la Ofiolita de Santa Elena, Escuder-Viruete et al. (2015) lo ubican entre el Cretácico Superior temprano y el Campaniano tardío, según su modelo geodinámico y las consideraciones de Escuder-Viruete y Baumgartner (2014); Frisch, Meschede y Sick, (1992); y Tournon (1994). El sobrecorrimiento de la Ofiolita de Santa Elena tuvo lugar entre el Cretácico Superior temprano y el Campaniano tardío.

Eoceno Superior - Mioceno: se compuso de esfuerzos NNE-SSW que generaron fallas inversas y pliegues en las rocas sedimentarias del Cretácico terminal - Paleógeno, con orientación preferencial E-W (Astorga et al., 1991; Denyer, Vargas, et al., 2019; Gursky, 1988; Kuijpers, 1980; Ladd, 1976; Meschede \& Frisk, 1998). Su génesis está dada por la interacción convergente entre las placas Norteamericana y Suramericana (Gursky, 1988; Ladd, 1976).
Cuaternario: según las estructuras evidenciadas hacia el sureste del área de estudio (eje de basculamiento y buzamientos fotogeológicos en las rocas de las formaciones Bagaces, Liberia y Monteverde) se evidencia una compresión con una dirección aproximada hacia el E.

\section{HISTORIA GEOLÓGICA}

La geología del sector pericostero del noroeste de Costa Rica muestra eventos geológicos únicos respecto al resto del país. Estos están resumidos en la Tabla 1.

Jurásico al Cretácico Inferior ( 200 100 Ma): Representa el inicio del registro geológico en la región, con erupciones volcánicas submarinas acontecidas en la placa tectónica Farallón y dieron como resultado los petit-spots (Fig. 8A). Contemporáneamente se presentó la continua muerte de organismos marinos de tamaños micrométricos, en su mayoría radiolarios, que fueron depositados con sedimentos finos en el piso oceánico, cuya litificación de estos microcomponentes genera rocas denominadas radiolaritas. Estos productos conforman el Complejo Acrecional de Santa Rosa.

Cretácico Inferior (145 - 100 Ma): En esta época se infiere la formación de la Ofiolita de Santa Elena en el manto superior de la Tierra. Esta ofiolita corresponde a un terreno alóctono, que presenta al menos dos etapas magmáticas: una del manto con intrusión de diques de gabro pegmatíticos (emplazados por diferencias de presión que permitieron su movimiento por zonas de debilidad), y una segunda etapa intrusiva de diques de dolerita.

Seguidamente, la ofiolita fue afectada por esfuerzos tensionales a nivel geotectónico (Fig. 8B), que generaron fracturas abiertas de cientos de kilómetros. Las fracturas de estas dimensiones pueden llegar a provocar conexión del manto con la superficie terrestre, es decir la emersión de estas rocas desde el manto terrestre hasta la parte superior de la 
TABLA 1

Eventos geológicos singulares documentados en el noroeste de Costa Rica. Sup.: Superior, Dep.: Depositación

TABLE 1

Singular geologic events documented in the northwest of Costa Rica

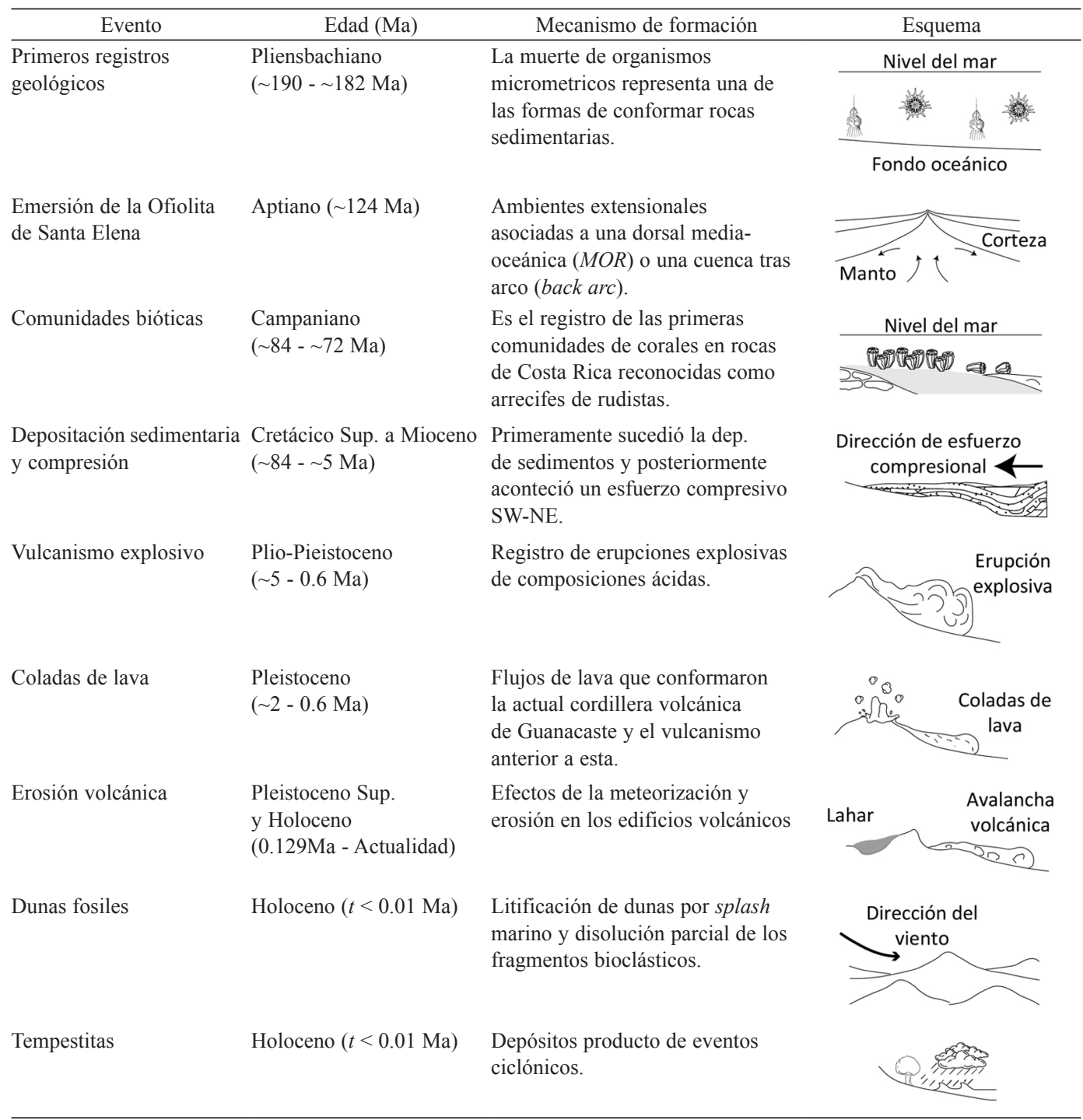

corteza terrestre. En el caso de la Ofiolita de Santa Elena no se ha determinado aún si estos ambientes extensionales se presentaron en una dorsal medio-oceánica $(M O R)$ - producto de la separación de América del Norte de América del Sur, o en una cuenca tras arco (back arc: Madrigal et al., 2015).
En esta misma época se generaron otros eventos ígneos a consecuencia de la actividad volcánica no asociada con la Ofiolita de Santa Elena, pero si típico en la corteza oceánica, como: (1) el Complejo Ígneo Estratificado de Bahía Nancite, que posiblemente emergió por el mismo medio y al mismo tiempo que la 
ofiolita, y (2) los Basaltos de las Islas Murciélago, producto de erupciones submarinas tipo gran provincia ígnea en la placa Pacífica.

\section{Cretácico Superior (100 - 66 Ma):}

Durante el Cretácico Superior las rocas de la Ofiolita de Santa Elena comenzaron su traslado tectónico desde el plano abisal, con profundidades entre 3000 y $6000 \mathrm{~m}$ b.n.m., hasta una plataforma continental con profundidad variable entre 0 y $200 \mathrm{~m}$ b.n.m. Esta plataforma contenía condiciones favorables para el crecimiento de comunidades de arrecifes dominadas por rudistas y nerineas reconocidas hoy en día como la Formación El Viejo (Fig. 8C).

En los bordes de estas plataformas es común que se generen flujos de detritos $\mathrm{y}$ avalanchas de escombros, emplazados y depositados en el talud continental, producto del retrabajo de sedimentos y el levantamiento tectónico por actividad sísmica. Este episodio está representado por la Formación Santa Ana. De forma sincrónica al crecimiento de arrecifes y los episodios de retrabajo y sedimentación, se dio el acarreo y posterior acumulación de materiales finos a muy finos y biogénicos (muerte de microorganismos) por acción de corrientes marinas. Estos depósitos son identificados al norte de la península de Santa Elena como la Formación Piedras Blancas.

El traslado de las rocas del Nappe fue consecuencia de una etapa con esfuerzos compresivos que generó un sistema de fallamiento inverso, donde una litología o unidad de roca más antigua se movió hasta quedar sobre una litología más joven. Estos esfuerzos se asocian al evento tectónico de inicios del Campaniano. Este evento provocó la interacción entre la Ofiolita de Santa Elena (litología más antigua) y el Complejo Acrecional de Santa Rosa (litología más joven), formando la Brecha Tectónica.

Paleoceno (66 - $56 \mathrm{Ma})$ : Se formaron depósitos de deslizamientos y corrientes de turbidez en los taludes continentales (Fig. 8D). Estos procesos ocurrieron por la inestabilidad en los sedimentos, y fueron disparados por sismos o cambios en el régimen y cantidad de sedimentación por aporte de material terrígeno relacionado a actividad volcánica y la acción de la erosión. Estos depósitos son agrupados en la Formación Rivas.

La depositación en ambientes más profundos en el perfil batimétrico respecto a los depósitos del Cretácico Superior demuestran una transgresión producida por la subsidencia tectónica en la región estudiada. La subsidencia tectónica es el progresivo hundimiento de la corteza por el movimiento generado en las fallas geológicas.

Eoceno (56 - 34 Ma): Representa una época de somerización o regresión marina; es decir, un cambio en los ambientes de depositación que varían desde profundos a someros con abundancia de ondulitas (Fig. 8E). Las ondulitas se generan por movimientos tipo vaivén de agua, como el movimiento del agua salada en las playas. Estas rocas son nombradas como Formación Brito.

El relleno de la cuenca se asocia a un cambio en el régimen de depositación en la cuenca, por aporte continuo de sedimentos desde un arco de islas activo, o el evento tectónico a mitad del Eoceno. Los eventos tectónicos son sucesos donde se presentan cambios en las condiciones de deformación que modifican el patrón de esfuerzos y por tanto las condiciones de depositación dentro de una cuenca. Algunos ejemplos de eventos tectónicos son cambios en la dirección de movimiento de placas tectónicas, desplazamientos a lo largo de fallas o levantamientos regionales. Este evento tectónico marca el inicio de una fase compresiva que dio origen al tren de pliegues entre el golfo de Santa Elena y bahía de Salinas.

Oligoceno (34 - 23 Ma): Durante el Oligoceno continuó el relleno de la cuenca representado por la fase final de somerización. Esta somerización a inicios del Oligoceno está representada por depósitos con estructuras sedimentarias que evidencian picos de energía, corrientes multidireccionales y sedimentos en suspensión, los cuales son típicos de tormentas en zonas de poca profundidad 


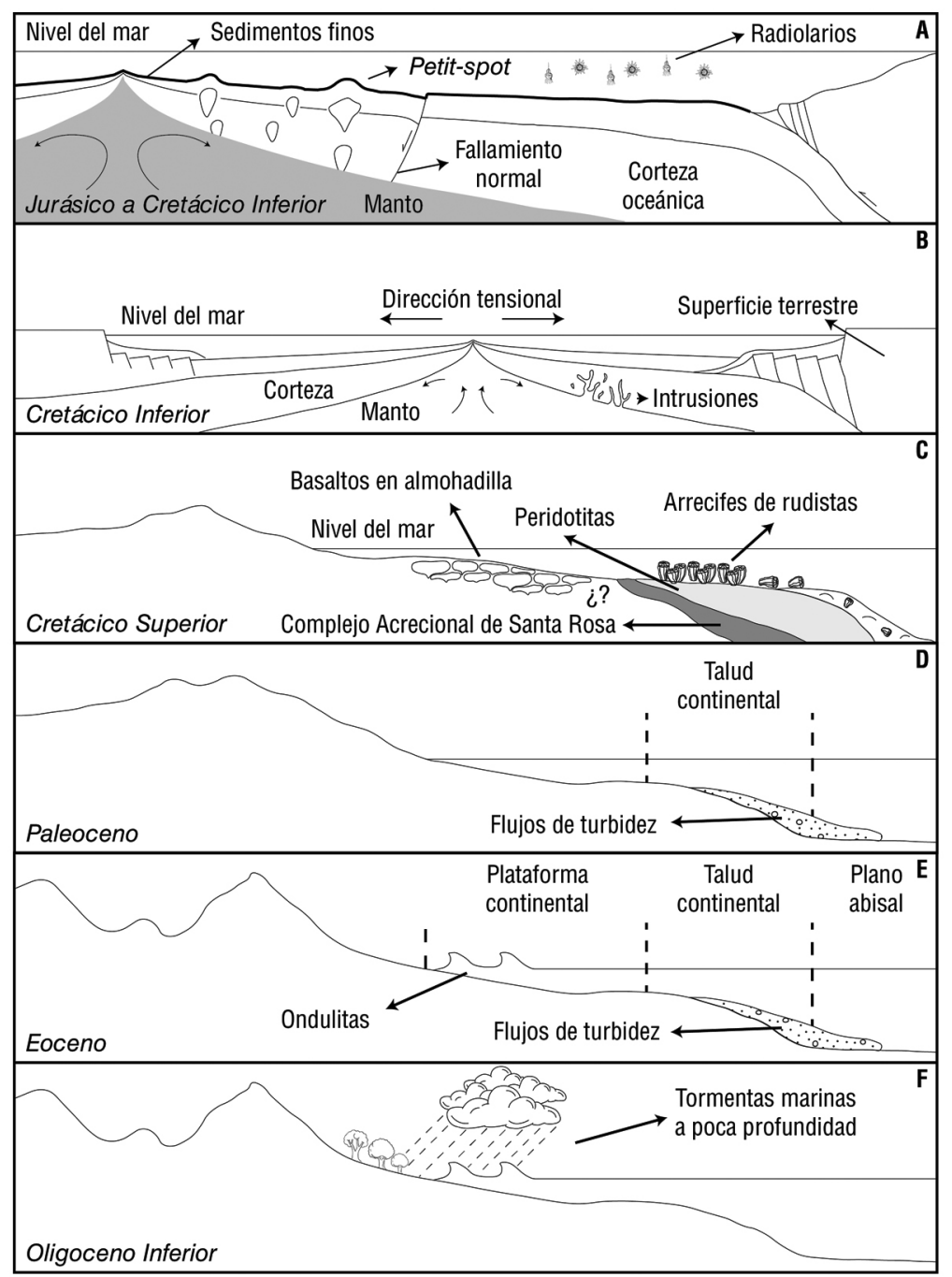

Fig. 8. Procesos depositacionales del Jurásico al Oligoceno Inferior. Fig. 8. Depositional processes from Jurassic to Lower Oligocene.

(Fig. 8F). Estos depósitos se identifican como Formación Junquillal.

Para finales del Oligoceno el registro geológico lo comprende la Formación Punta Pelada. Durante esta época, predominó un ambiente marino somero típico de arrecifes coralinos de poca profundidad con influencia de corrientes fuertes, un aporte terrígeno continuo, cambios frecuentes de energía en el medio y cambios en el nivel relativo del mar (Fig. 9A).
Mioceno (23.03 - 5.3 Ma): El Mioceno no presenta registro litológico, por el levantamiento abrupto asociado al final de la etapa tectónica compresiva que generó el tren de pliegues entre el golfo de Santa Elena y bahía de Salinas (Fig. 9B).

Plioceno (5.3 - 2.58 Ma): La tectónica compresiva durante el Mioceno contribuiría a la elevación del arco de islas volcánico con 


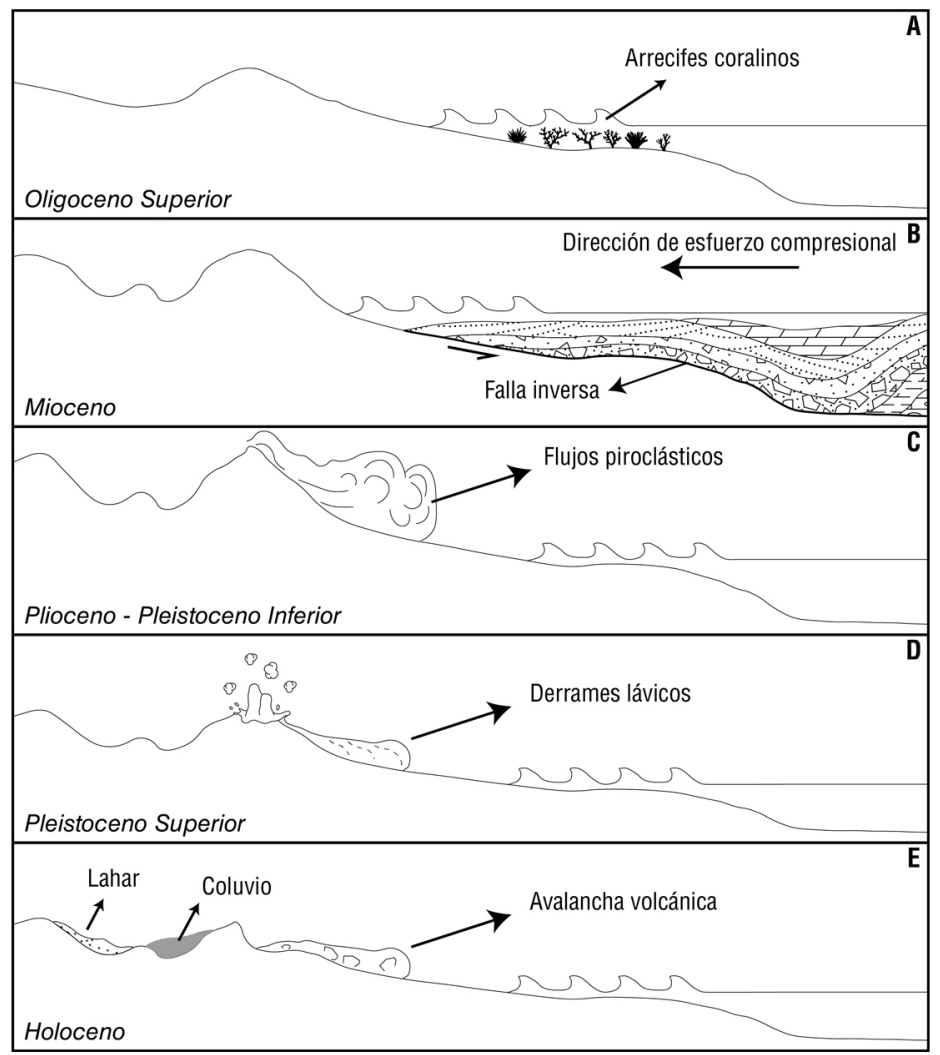

Fig. 9. Procesos depositacionales del Oligoceno Superior al Holoceno (presente).

Fig. 9. Depositional processes since Upper Oligocene to Holocene (present).

un sustrato de las sedimentitas plegadas, sobre las cuales se depositaron los productos de las grandes erupciones volcánicas explosivas (Fig. 9C). Este tipo de actividad permitió la colmatación de la cuenca y el término de la depositación bajo el nivel del mar. Además, generó los relieves planos que dieron paso a la Meseta Volcánica de Santa Rosa.

Pleistoceno (2.58 - 0.01 Ma): A inicios del Pleistoceno todavía imperaban las condiciones de vulcanismo explosivo. Al mismo tiempo hubo un cambio geotectónico en los esfuerzos que provocó el eje de basculamiento, por ende la leve inclinación de la Meseta de Santa Rosa hacia el este franco. Se construyeron los edificios previos a la cordillera volcánica actual (Formación Monteverde), con lavas predominantes y algunos eventos de ignimbritas y la formación de calderas, y la construcción de la cordillera volcánica de Guanacaste (macizos Orosí-Cacao y Rincón de la Vieja).

En la etapa final del Pleistoceno y el inicio del Holoceno se consolidó un predominio de derrames lávicos o coladas de lava y depósitos lacustres (Fig. 9D).

Holoceno (0.01 Ma - actualidad): El Holoceno para el noroeste de Costa Rica comprende el estado actual de evolución de la Cordillera de Guanacaste, con fases constructivas (lavas predominantes y piroclastos subordinados) y fases erosivas que incluyen la génesis de eventos laháricos y de avalanchas volcánicas como consecuencia de la denudación física y actividad eruptiva de los macizos Orosí - Cacao y Rincón de la Vieja (Fig. 9E). Otros depósitos fueron producto de la erosión 
y depositación eólica, que dieron lugar a dunas y paleodunas, erosión gravitatoria con la fragmentación de las rocas para generar coluvios, y erosión hídrica como lo son las tempestitas y los depósitos aluviales, producto de la acumulación de sedimentos finos a gruesos en zonas donde se presenta agua en movimiento.

\section{Conclusiones}

El contexto geológico mostrado en esta investigación presenta elementos geológicos únicos a nivel nacional como las dunas fósiles, depósitos producto de fuertes tormentas, rocas del manto terrestre, rocas asociadas con la evolución biótica de arrecifes coralinos dominados por rudistas durante el Cretácico Superior (hasta 83.6 Ma) y el plegamiento de rocas sedimentarias que tuvieron procesos de erosión y depositación, conformando una discordancia, la cual luego fue parcialmente cubierta por depósitos ignimbríticos voluminosos. Además, en esta zona se tiene el reporte de la datación más antigua de Costa Rica correspondiente al Pliensbachiano - Jurásico Inferior ( 190.8 $\sim 182.7$ Ma: DeWever et al., 1985).

Esta investigación considera que las rocas del área de estudio se pueden incluir en cinco grupos según sus características: rocas de afinidad oceánica u Ofiolita de Santa Elena, rocas sedimentarias, eventos extrusivos de tipo explosivo, rocas efusivas y depósitos recientes. Además, las rocas del área de estudio evidencian al menos cuatro fases compresivas: Cretácico Inferior ( 145 - 100.5 Ma), Cretácico Superior temprano - Campaniano temprano ( 100.5 - 72.1 Ma), Eoceno Superior - Mioceno (37.8 - 5.333 Ma) y Cuaternario (2.58 Ma - hoy en día).

Las morfologías y la constitución de los suelos son producto de los procesos geológicos acaecidos en el noroeste de Costa Rica. Cada una de estas fases tiene injerencias en el terreno respecto a las especies vegetales encontradas y el uso de la tierra. Por lo tanto, es posible establecer una relación directa entre la geosfera y la biosfera. Esta relación permite delimitar cuatro zonas geológicas que según su afinidad condicionan la vegetación y la fauna, por lo que suelen ser fáciles de reconocer por sus cambios abruptos. La primera zona está conformada por las rocas de la Ofiolita de Santa Elena que no permiten el desarrollo habitual de la vegetación, solamente árboles de tamaño pequeño, por su alto contenido de magnesio y otros elementos. Las rocas sedimentarias representan la segunda zona, que presenta una mayor afinidad con los componentes bióticos. Por tanto, la mayor diversidad de especies está presente a donde afloran estas rocas. La tercera zona son las planicies volcánicas producto de los eventos extrusivos de tipo explosivo, las cuales limitan esta diversidad y se reconoce vegetación con ausencia de hojas o son de tamaño reducido. Por último, las rocas efusivas con piroclastos subordinados representan terrenos muy fértiles con las condiciones ideales para el desarrollo intenso de vegetación y cultivos.

Declaración de ética: los autores declaran que todos están de acuerdo con esta publicación y que han hecho aportes que justifican su autoría; que no hay conflicto de interés de ningún tipo; y que han cumplido con todos los requisitos y procedimientos éticos y legales pertinentes. Todas las fuentes de financiamiento se detallan plena y claramente en la sección de agradecimientos. El respectivo documento legal firmado se encuentra en los archivos de la revista.

\section{AGRADECIMIENTOS}

A Karla Vásquez F., Yoselyn Álvarez S. y Adrián Obando A. por sus valiosos aportes durante la realización del texto de este artículo. También a Róger Blanco y Alejandro Masís, del Área de Conservación Guanacaste, por permitir el desarrollo de esta investigación. Además, a Marco Díaz Segura del Museo +UCR por facilitar algunas fotografías mostradas en este manuscrito y a los revisores anónimos por sus valiosos aportes y comentarios en pro de mejorar el documento final. Este artículo fue parte del proyecto B0-242 del Centro de Investigación en Ciencias Geológicas de la Universidad 


\section{de Costa Rica, titulado Fortalecimiento de la investigación en Estratigrafía y Tectónica.}

\section{RESUMEN}

Introducción: El noroeste de Costa Rica representa un área con una alta riqueza geológica que evidencia rocas generadas en diferentes ambientes, como plano abisal, talud continental, plataforma continental, volcánicos continentales efusivos y explosivos, volcánicos submarinos, costeros, erosivos fluviales, erosivos gravitatorios, de intrusión y el manto terrestre.

Objetivo: Describir el contexto geológico actual del noroeste de Costa Rica, mediante el análisis y recopilación de datos de campo, geoquímicos, petrológicos, estructurales, paleontológicos y radiométricos con el fin de reconstruir los eventos y etapas de deformación desde el Jurásico a la actualidad.

Métodos: Se hizo una recopilación bibliográfica de estudios en diversas ramas geológicas para establecer un estado del arte del extremo noroeste de Costa Rica.

Resultados: La historia geológica representa el registro en rocas desde el Jurásico al Holoceno - actualidad con once etapas definidas a partir de interpretaciones petrológicas, estructurales, geocronológicas, estratigráficas y paleontológicas agrupadas en tres etapas de depositación y afectadas por cuatro fases tectónicas compresivas.

Conclusiones: Las etapas de depositación corresponden con una primera etapa magmática con afinidad oceánica entre el Jurásico y el Cretácico Superior, una segunda etapa predominantemente sedimentaria con un rango de edad entre el Cretácico Superior y el Oligoceno, y por último una etapa volcánica efusiva - explosiva ubicada desde el Plioceno hasta la actualidad. Las fases tectónicas se asocian con diferentes eventos entre placas. La primera se dio en el Cretácico Inferior y su principal resultado visible fue la emersión de la Ofiolita de Santa Elena; la segunda sucedió del Cretácico Superior temprano al Campaniano y su reconocimiento está ligado a la posición actual de la Ofiolita de Santa Elena y sus estructuras circundantes; la tercera fase aconteció desde el Eoceno Superior hasta el Mioceno y su principal producto fue la generación del tren de pliegues sedimentarios del Golfo de Santa Elena a bahía de Salinas; y por último se presenta una fase Cuaternaria que originó el eje de basculamiento de los productos piroclásticos frente a la cordillera volcánica de Guanacaste.

Palabras clave: Ofiolita de Santa Elena; historia geológica; compresión; erupción volcánica; Guanacaste; fase tectónica; roca sedimentaria.

\section{REFERENCIAS}

Aguilar, T. (1990). La evolución de las comunidades de moluscos y su relación con el desarrollo geológico del sur de América Central. Revista Geológica de América Central, 11, 51- 57.

Aguilar, T., \& Cortés, J. (2001). Arrecifes coralinos del Oligoceno Superior-Mioceno Inferior, de Turrialba, Costa Rica. Revista de Biología Tropical, 49(Suplemento 2), S203-S213.

Aguilar, T., \& Denyer, P. (2002). Primer hallazgo de trigonias (Mollusca: bivalvia) cretácicas de Costa Rica (Tortugal, Guanacaste): Geología, estratigrafía y paleontología. Revista Geológica de América Central, 26, 53-63.

Aguilar, T., \& Denyer, P. (2019). Estratigrafía sedimentaria. En P. Denyer (Ed.), Perspectiva geológica del noroeste de Costa Rica: historia, evolución y cartografia (pp. 43-100). San José, Costa Rica: Editorial Universidad de Costa Rica.

Aguilar, T., Denyer, P., \& Arredondo, S. (2020). Tempestita del Holoceno Medio en la isla San José, Área de Conservación Guanacaste, Costa Rica. Revista Geológica de América Central, 62, 48-64.

Aiazzi, D., Fiorletta, M., Civelli, G., Chiesa, S., \& Alvarado, G. E. (2004). Geología de la hoja Cañas. Revista Geológica de América Central, 30, 215-223.

Alvarado, G. E. (1984). Aspectos petrológicos-geológicos de los volcanes y unidades lávicas del Cenozoico Superior de Costa Rica (Tesis de Licenciatura). Universidad de Costa Rica, San José, Costa Rica.

Alvarado, G. E., \& Denyer, P. (2019). Estratigrafía volcánica del Neógeno y Cuaternario. En P. Denyer (Ed.), Perspectiva geológica del noroeste de Costa Rica: historia, evolución y cartografia (pp. 101-238). San José, Costa Rica. Editorial Universidad de Costa Rica.

Alvarado, G. E., \& Gans, P. B. (2012). Síntesis geocronológica del magmatismo, metamorfismo y metalogenia de Costa Rica, América Central. Revista Geológica de América Central, 46, 7-122.

Alvarado, G. E., Vega, E., Chaves, J., \& Vásquez, M. (2004). Los grandes deslizamientos (volcánicos y no volcánicos) de tipo debris avalanche en Costa Rica. Revista Geológica de América Central, 30, 83-99.

Andjić, G., Baumgartner-Mora, C., \& Baumgartner, P. O. (2016). An upper Paleogene shallowing-upward sequence in the southern Sandino Forearc Basin (NW Costa Rica): response to tectonic uplift. Facies, 62(2), 1-35.

Arias, M. (2002). Petrografia y geoquímica de las rocas del Complejo Ígneo Estratificado de Bahía Nancite y su relación con los filones basálticos, península de Santa Elena, Costa Rica. (Tesis de Licenciatura). Universidad de Costa Rica, San José, Costa Rica. 
Astorga, A. (1987). El Cretácico Superior y el Paleógeno de la vertiente pacífica de Nicaragua meridional y Costa Rica septentrional: origen, evolución y dinámica de las cuencas profundas relacionadas al margen convergente de Centroamérica. (Tesis de Licenciatura). Universidad de Costa Rica, San José, Costa Rica.

Astorga, A., Fernández, J. A., Barboza, G., Campos, L., Obando, J., Aguilar, A., \& Obando, L. G. (1991). Cuencas sedimentarias de Costa Rica: Evolución geodinámica y potencial de hidrocarburos. Revista Geológica de América Central, 13, 25-59.

Auer, W. F. (1942). Summary Report of Paleontology of Pacific Coast Area, Nicaragua. Managua, Nicaragua: Catastro.

Azéma, J., Bourgois, J., Baumgartner, P. O., Tournon, J., Desmet, A., \& Aubouin, J. (1985). A tectonic crosssection of the Costa-Rican Pacific littoral as a key to the structure of the landward slope of the Middle America Trench off Guatemala. Initial Report of the Deep-Sea Drilling Project, 84, 831-850.

Barrantes, G. A. (2018). Modelo volcano-sedimentario e historia geológica del sector noreste de Lomas Barbudal (Guanacaste, Costa Rica). (Tesis de Licenciatura). Universidad de Costa Rica, San José, Costa Rica.

Barwick, M., \& Schans, A. V. D. (2004). Tropical \& subtropical trees, London, United Kingdom, Thames \& Hudson Ltd.

Baumgartner, P. O., \& Denyer, P. (2006). Evidence for middle Cretaceous accretion at Santa Elena Peninsula (Santa Rosa Accretionary Complex), Costa Rica. Geologica Acta, 4(1-2), 179-191.

Baumgartner, P. O., Flores, K., Bandini, A. N., Girault, F., \& Cruz, D. (2008). Upper Triassic to Cretaceous radiolaria from Nicaragua and northern Costa RicaThe Mesquito composite oceanic terrane. Ofioliti, 33(1), 1-19.

Baumgartner, P. O., Mora, C. R., Butterlin, J., Sigal, J., Glacon, G., Azéma, J., \& Bourgois, J. (1984). Sedimentación y paleogeografía del Cretácico y Cenozoico del litoral pacífico de Costa Rica. Revista Geológica de América Central, 1, 57-136.

Baumgartner-Mora, C., \& Denyer, P. (2002). CampanianMaastrichtian limestone with larger foraminifera from Peña Bruja rock (Santa Elena Peninsula). Revista Geológica de América Central, 26, 85-89.

Bohnenberger, O. H. (1968). Un reconocimiento fotogeológico en Guanacaste (Informe Interno). Naciones Unidas, San José, Costa Rica.

Bourgois, J., Azéma, J., Baumgartner, P. O., Tournon, J., Desmet, A., \& Aubouin, J. (1984). The geologic history of the Caribbean-Cocos plate boundary with special reference to the Nicoya ophiolite complex
(Costa Rica) and DSDP results (Legs 67 and 84 off Guatemala): A synthesis. Tectonophysics, 108(1-2), $1-32$.

Boza, S. (2019). Vachellia collinsi (Fabaceae) - Cornizuelo. Área de Conservación Guanacaste. https://www. acguanacaste.ac.cr/arboretum/4828-cornizuelo

Branney, M. J., \& Kokelaar, P. (2002). Pyroclastic density currents and the sedimentation of ignimbrites. Geological Society of London, 27, 1-152.

Buchs, D. M., Pilet, S., Cosca, M., Flores, K. E., Bandini, A. N., \& Baumgartner, P. O. (2013). Low-volume intraplate volcanism in the Early/Middle Jurassic Pacific basin documented by accreted sequences in Costa Rica. Geochemistry, Geophysics, Geosystems, 14(5), 1552-1568.

Calvo, C. (1987). Las calizas neríticas de la Vertiente Pacifica del Norte de Costa Rica y sur de Nicaragua. Épocas y Sistemas Asociados con la apertura y evolución del margen convergente de la América Central Meridional. (Tesis de Licenciatura). Universidad de Costa Rica, San José, Costa Rica.

Carcavilla, L., Durán, J. J., \& López-Martínez, J. (2008). Geodiversidad: concepto y relación con el patrimonio geológico. Geo-Temas, 10, 1299-1303.

Chaves, R., \& Sáenz, R. (1974). Geología de la Cordillera de Tilarán (Proyecto Aguacate, $2^{\mathrm{a}}$ fase). Informe Técnico: Notas Geológicas, 12(53), 11-49.

Chiesa, S., Alvarado, G. E., Pecchio, M., Corella, M., \& Zanchi, A. (1994). Contribution to petrological and stratigraphical understanding of the Cordillera de Guanacaste lava flows, Costa Rica. Revista Geológica de América Central, 17, 19-43.

Chiesa, S., Civelli, G., Gillot, P. Y., Mora, O., \& Alvarado, G. E. (1992). Rocas piroclásticas asociadas con la formación de la caldera de Guayabo, Cordillera de Guanacaste, Costa Rica. Revista Geológica de América Central, 14, 59-75.

Cigolini, C., \& Chaves, R. (1986). Geological, petrochemical and metallogenic characteristics of the Costa Rican gold belt: Contribution to new explorations. Geologische Rundschau, 75(3), 737-754.

Civelli, G., Locati, U., Bigioggero, B., Chiesa, S., Alvarado, G. E., \& Mora, O. (2005). Geología de la hoja Tierras Morenas. Revista Geológica de América Central, 33, 99-110.

CONABIO (2020). Catálogo de autoridades taxonómicas de especies de flora y fauna con distribución en México. México. CONABIO. https://www.snib.mx/

Cottle, R. (2004). Linking Geology and Biodiversity. English Nature Research Reports 562, 1-91. 
David, A. (2005). The Bagaces Formation in the Guanacaste Province, Costa Rica: Refined Stratigraphy and Petrology. (Disertación Doctoral). ChristianAlbrechts-Universität, Kiel, Alemania.

Deering, C. D., Vogel, T. A., Patino, L. C., \& Alvarado, G. E. (2007). Origin of distinct silicic magma types from the Guachipelín Caldera, NW Costa Rica: Evidence for magma mixing and protracted subvolcanic residence. Journal of Volcanology and Geothermal Research, 165(3-4), 103-126.

Deering, C. D., Vogel, T. A., Patino, L. C., Szymanski, D. W., \& Alvarado, G. E. (2012). Magmatic processes that generate chemically distinct silicic magmas in NW Costa Rica and the evolution of juvenile continental crust in oceanic arcs. Contributions to Mineralogy and Petrology, 163(2), 259-275.

Dengo, G. (1962). Estudio geológico de la región de Guanacaste, Costa Rica (Informe Interno). San José, Costa Rica: Compañía Petrolera de Costa Rica.

Denyer, P. (Ed.). (2019). Perspectiva geológica del noroeste de Costa Rica: Historia, evolución y cartografia. San José, Costa Rica: Editorial Universidad de Costa Rica.

Denyer, P., Aguilar, T., \& Montero, W. (2014). Cartografía Geológica de la península de Nicoya. Revista Geológica de América Central, Número Especial 2014: 30 Aniversario, 173-183.

Denyer, P., Cortés, J., \& Cárdenes, G. (2005). Hallazgo de dunas fósiles de final del Pleistoceno en las islas Murciélago, Costa Rica. Revista Geológica de América Central, 33, 29-44.

Denyer, P., \& Gazel, E. (2009). The Costa Rican Jurassic to Miocene oceanic complexes: Origin, tectonics and relations. Journal of South American Earth Sciences, $28,429-442$.

Denyer, P., Gazel, E., Aguilar, T., Madrigal, P., \& Chavarría, M. M. (2019). Mapa geológico de la hoja Santa Elena. Escala, 1:50000. Centro de Investigación en Ciencias Geológicas de la UCR.

Denyer. P., Vargas, C., Lücke, O., \& Solano, J. P. (2019). Deformación y geomorfología. En P. Denyer (Ed.) Perspectiva geológica del noroeste de Costa Rica: historia, evolución y cartografia (pp. 275-299). San José, Costa Rica: Editorial Universidad de Costa Rica.

DeWever, P., Azéma, J., Tournon, J., \& Desmet, A. (1985) Découverte de matériel océanique du Lias-Dogger inférieur dans la péninsule de Santa Elena (Costa Rica, Amérique Centrale). Comptes-rendus des séances de l'Académie des sciences. Série 2, Mécaniquephysique, chimie, sciences de l'univers, sciences de la terre, 300(15), 759-764.
Dóndoli, C. (1950). Liberia y sus alrededores. Suelo Tico (Costa Rica), 4(18-19), 65-69.

Escuder-Viruete, J., Andjić, G., Baumgartner-Mora, C., Baumgartner, P. O., Castillo-Carrión, M., \& Gabites, J. (2019). Origin and geodynamic significance of the Siuna Serpentinite Mélange, Northeast Nicaragua: Insights from the large-scale structure, petrology and geochemistry of the ultramafic blocks. Lithos, $340,1-19$.

Escuder-Viruete, J., \& Baumgartner, P. O. (2014). Structural evolution and deformation kinematics of a subduction-related serpentinite-matrix mélange, Santa Elena Peninsula, northwest Costa Rica. Journal of Structural Geology, 66, 356-381.

Escuder-Viruete, J., Baumgartner, P. O., \& Castillo-Carrión, M. (2015). Compositional diversity in peridotites as result of a multi-process history: The Pacific-derived Santa Elena ophiolite, northwest Costa Rica. Lithos, $231,16-34$

Espinoza, R., Guadamuz, A., Pérez, D., Chavarría, F., \& Masís, A. (2000). Bursera schlechtendalii (Burseraceae). Área de Conservación Guanacaste, Costa Rica. https://www.acguanacaste.ac.cr/paginas_especie/ plantae online/magnoliophyta/burseraceae/bursera schlechtendalii/b_schlechtendalii27feb2000/b_schlechtendalii27feb2000.html

Flores, K., Denyer, P., \& Aguilar, T. (2003). Nueva propuesta estratigráfica: geología de las hojas Matambú y Talolinga Guanacaste, Costa Rica. Revista Geológica de América Central, 28, 131-138.

Frisch, W., Meschede, M., \& Sick, M. (1992). Origin of the Central American ophiolites: Evidence from paleomagnetic results. Geological Society of America Bulletin, 104(10), 1301-1314.

Gallagher, G. (2018). Quercus oleoides. The IUCN Red List of Threatened Species 2018: e.T194209A2304166. https://dx.doi.org/10.2305/IUCN.UK.2018-2.RLTS. T194209A2304166.en

Gamboa, V. (2013). Paleoecología, estratigrafía y sedimentología del depósito de Diatomita Loma Camastro, Liberia - Guanacaste. (Tesis de Licenciatura). Universidad de Costa Rica, San José, Costa Rica.

Gazel, E., Denyer, P., \& Baumgartner, P. O. (2006). Magmatic and geotectonic significance of Santa Elena peninsula, Costa Rica. Geologica Acta, 4(1-2), 193-202.

Geldmacher, J., Hoernle, K., Van Den Bogaard, P., Hauff, F., \& Klügel, A. (2008). Age and geochemistry of the Central American forearc basement (DSDP Leg 67 and 84): Insights into Mesozoic arc volcanism and seamount accretion on the fringe of the Caribbean LIP. Journal of Petrology, 49(10), 1781-1815. 
Gillot, P. Y., Chiesa, S., \& Alvarado, G. E. (1994). Chronostratigraphy of upper Miocene-Quaternary volcanism in northern Costa Rica. Revista Geológica de América Central, 17, 45-53.

Gómez, M., (1992). Evaluación de un yacimiento de diatomita en Quebrada Grande, Liberia, Guanacaste (Costa Rica). (Tesis de Licenciatura). Universidad de Costa Rica, San José, Costa Rica

Gursky, M. M. (1988). Análisis tectónico de la Península de Nicoya (Costa Rica) y su significado para el desarrollo estructural-geodinámico de América Central meridional. Revista Geológica de América Central, 8, 19-75.

Hallinan, S., \& Brown, G. (1995). Incremental collapse and stratocone growth within a funnel-shaped caldera, Guayabo, Costa Rica. Journal of Volcanology and Geothermal Research, 67(1-3), 101-122.

Hauff, F., Hoernle, K., \& Bogaard, P. (2000). Age and geochemistry of basaltic complexes in western C.R.: Contributions to the geotectonic evolution of Central America. Geochemistry, Geophysics, Geosystems, 1(5), 1019. doi: 10.1029/1999GC000020.

Herrera-Zúñiga, P., \& Vargas, A. E. (2012). Geología de Bahía Culebra, Guanacaste, Costa Rica. Revista de Biología Tropical, 60(Suplemento 2), S213-S223.

Hirano, N. (2011). Petit-spot volcanism: A new type of volcanic zone discovered near a trench. Geochemical Journal, 45(2), 157-167.

Hoffstetter, R., Dengo, G., \& Weyl, R. (1960). Introducción. Costa Rica. Lexique Stratigraphique International. Amérique Centrale. CNRS, París, 5(2), 227-306.

Hoffstetter, R., \& Zoppis de Bracci, L. (1960). Nicaragua: Lexique Stratigraphique International. Amerique Latine, 5, 171-224.

Kruckeberg, A. (2002). Geology and plant life. University of Washington Press. Seattle, WA.

Kuijpers, E. P. (1980). The geologic history of the Nicoya Ophiolite Complex, Costa Rica, and its geotectonic significance. Tectonophysics, 68(3-4), 233-255.

Jaccard, S., Münster, M., Baumgartner, P. O., BaumgartnerMora, C., \& Denyer, P. (2001). Barra Honda (Upper Paleocene-Iower Eocene) and el Viejo (CampanianMaastrichtian) carbonate platforms in the Tempisque Area (Guanacaste, Costa Rica). Revista Geológica de América Central, 24, 9-28.

Kempter, K. A. (1997). Geologic evolution of the Rincón de la Vieja volcanic complex, NW, Costa Rica. (Disertación Doctoral). University of Texas, Austin, United States.
Kussmaul, S., Tournon, J., \& Alvarado, G. E. (1994). Evolution of the Neogene to Quaternary igneous rocks of Costa Rica. Profil, 7, 97-123.

Ladd, J. W. (1976). Relative motion of South America with respect to North America and Caribbean tectonics. Geological Society of America Bulletin, 87(7), 969-976.

Madrigal, P., Gazel, E., \& Denyer, P., (2019). Petrogénesis ígnea del basamento. En P. Denyer (Ed.), Perspectiva geológica del noroeste de Costa Rica: historia, evolución y cartografia (pp. 9-42). San José, Costa Rica: Editorial Universidad de Costa Rica.

Madrigal, P., Gazel, E., Denyer, P., Smith, I., Jicha, B., Flores, K. E., ... Snow, J. (2015). A melt-focusing zone in the lithospheric mantle preserved in the Santa Elena Ophiolite, Costa Rica. Lithos, 230, 189-205.

Madrigal, P., Gazel, E., Flores, K. E., Bizimis, M., \& Jicha, B. (2016). Record of massive upwellings from the Pacific large low shear velocity province. Nature Communications, 7(1), 1-12.

Malavassi, E. (1961). Some Costa Rican larger foraminiferal localities. Journal of Paleontology, 35(3), 498-501.

Meschede, M., \& Frisch, W. (1994). Geochemical characteristics of basaltic rocks from the Central American ophiolites. Profil, 7, 71-85.

Meschede, M., Frisch, W., \& Sick, M. (1988). Interpretación geodinámica de los complejos ofiolíticos de Costa Rica. Revista Geológica de América Central, 8, 1-17.

Molina, F., Martí, J., Aguirre, G., Vega, E., \& Chavarría, L. (2014). Stratigraphy and structure of the Cañas Dulces caldera (Costa Rica). Geological Society of America Bulletin, 126(11-12), 1465-1480.

Pindell, J. L., Cande, S. C., Pitman III, W. C., Rowley, D. B., Dewey, J. F., LaBrecque, J., \& Haxby, W. (1988). A plate-kinematic framework for models of Caribbean evolution. Tectonophysics, 155(1-4), 121-138.

Pons, J. M., Vicens, E., \& Schmidt-Effing, R. (2016). Campanian rudists (Hippuritida, Bivalvia) from Costa Rica (Central America). Journal of Paleontology, 90(2), 211-238.

Ranero, C. R., von Huene, R., Flueh, E., Duarte, M., Baca, D., \& McIntosh, K. (2000). A cross section of the convergent Pacific margin of Nicaragua. Tectonics, 19(2), 335-357.

Schmidt-Effing, R. (1974). El primer hallazgo de amonites en América Central Meridional y notas sobre facies cretácicas en dicha región. Informe Semestral IGN, 1975(1), 53-61. 
Schmidt-Effing, R. (1980). Radiolarien der Mittel-Kreide aus dem Santa Elena-Massiv von Costa Rica. Neues Jahrbuch Geologie und Pläontologie, 160(2), 241-257.

Semm, W. (2005). Pliocene ignimbrites (Formación Bagaces) around Cañas, Guanacaste, Costa Rica. (Disertación Doctoral). Christian Albrechts University, Kiel, Germany.

Setzer, R. Y. (1994). Petrology and geochemistry of Costa Rica ignimbrites. (Disertación Doctoral). Wesleyan University, Middletown, Connecticut, United States.

Solano, J. P., Denyer, P., Pérez, W., Lücke, Ó. H., \& Madrigal, P. (2019). Formación Bagaces: caracterización de sus unidades para la identificación de depósitos y litofacies. Revista Geológica de América Central, 60, 7-39.

Solano, J. P., Denyer, P., \& Pérez, W. (2019). Caracterización petrográfica de la Formación Bagaces y las Lavas Pelón de la Bajura. En P. Denyer (Ed.). Perspectiva geológica del noroeste de Costa Rica: historia, evolución y cartografía (pp. 239-274). San José, Costa Rica: Editorial Universidad de Costa Rica.

Standley, P. C. \& Steyermark, J. A. (1946). Flora of Guatemala, Chicago, Illinois, United States, Chicago Natural History Museum.

Szymanski, D. W., Patino, L. C., Vogel, T. A., \& Alvarado, G. E. (2013). Evaluating complex magma mixing via polytopic vector analysis (PVA) in the Papagayo Tuff, northern Costa Rica: Processes that form continental crust. Geosciences, 3(3), 585-615.

Taylor, N. P. (1991). The genus Melocactus (Cactaceae) in Central and South America. Bradleya 9, 1-80.
Tournon, J. (1984). Magmatismes du Mesozoique a l'Actuel en Amerique Centrale: L'example de Costa Rica, des Ophiolites aux Andesites (Disertación Doctoral). Université Pierre et Marie Curie, París, France.

Tournon, J. (1994). The Santa Elena Peninsula: an ophiolitic nappe and a sedimentary volcanic relative autochthonous. Profil, 7, 87-96.

Tournon, J., \& Bellon, H. (2009). The southern Central America puzzle: Chronology and structure. A review. Revista Geológica de América Central, 40, 11-47.

Vogel, T. A., Patino, L. C., Alvarado, G. E., \& Gans, P. B. (2004). Silicic ignimbrites within the Costa Rican volcanic front: evidence for the formation of continental crust. Earth and Planetary Science Letters, 226(1-2), 149-159.

Vogel, T. A., Patino, L. C., Eaton, J. K., Valley, J. W., Rose, W. I., Alvarado, G. E., \& Viray, E. L. (2006) Origin of silicic magmas along the Central American volcanic front: Genetic relationship to mafic melts. Journal of Volcanology and Geothermal Research, 156(3-4), 217-228

Zaccarini, F., Garuti, G., Proenza, J. A., Campos, L., Thalhammer, O. A., Aiglsperger, T., \& Lewis, J. F. (2011). Chromite and platinum group elements mineralization in the Santa Elena Ultramafic Nappe (Costa Rica): geodynamic implications. Geologica Acta, 9(3-4), 407-423.

Zamora, N., Méndez, J., Barahona, M., \& Sjöbohm, L. (2004). Volcano-estratigrafía asociada al campo de domos de Cañas Dulces, Guanacaste, Costa Rica. Revista Geológica de América Central, 30, 41-58.

Zoppis Bracci, L., \& Del Giudice, D. (1958). Geología de la costa del Pacífico de Nicaragua. Boletín del Servicio Geológico Nacional de Nicaragua, 2, 21-65. 